\title{
Complex Visual Motion Representation in Mouse Area V1
}

\author{
Ganna Palagina, ${ }^{1,2}$ Jochen F. Meyer, ${ }^{1}$ and $@$ Stelios M. Smirnakis ${ }^{1,2}$ \\ ${ }^{1}$ Department of Neurology, Baylor College of Medicine, Houston, Texas 77030, and ²Brigham and Women's Hospital and Jamaica Plain Veterans \\ Administration Hospital, Harvard Medical School, Boston, Massachusetts 02115
}

Rodent visual cortex has a hierarchical architecture similar to that of higher mammals (Coogan and Burkhalter, 1993; Marshel et al., 2011; Wang et al., 2012). Although notable differences exist between the species in terms or receptive field sizes and orientation map organization (Dräger, 1975; Gattass et al., 1987; Van den Bergh et al., 2010), mouse V1 is thought to respond to local orientation and visual motion elements rather than to global patterns of motion, similar to V1 in higher mammals (Niell and Stryker, 2008; Bonin et al., 2011). However, recent results are inconclusive: some argue mouse V1 is analogous to monkey V1 (Juavinett and Callaway, 2015); others argue that it displays complex motion responses (Muir et al., 2015). We used type I plaids formed by the additive superposition of moving gratings (Adelson and Movshon, 1982; Movshon et al., 1985; Albright and Stoner, 1995) to investigate this question. We show that mouse V1 contains a considerably smaller fraction of component-motion-selective neurons $(\sim 17 \% \mathrm{vs} \sim 84 \%)$, and a larger fraction of patternmotion-selective neurons $(\sim 10 \%$ vs $<1.3 \%)$ compared with primate/cat V1. The direction of optokinetic nystagmus correlates with visual perception in higher mammals (Fox et al., 1975; Logothetis and Schall, 1990; Wei and Sun, 1998; Watanabe, 1999; Naber et al., 2011). Measurement of optokinetic responses to plaid stimuli revealed that mice demonstrate bistable perception, sometimes tracking individual stimulus components and others the global pattern of motion. Moreover, bistable optokinetic responses cannot be entirely attributed to subcortical circuitry as V1 lesions alter the fraction of responses occurring along pattern versus component motion. These observations suggest that area V1 input contributes to complex motion perception in the mouse.

Key words: area V1; bistable stimuli; mouse; plaids

\section{Significance Statement}

Area V1 in the mouse is hierarchically similar but not necessarily identical to area V1 in cats and primates. Here we demonstrate that area V1 neurons process complex motion plaid stimuli differently in mice versus in cats or primates. Specifically, a smaller proportion of mouse V1 cells are sensitive to component motion, and a larger proportion to pattern motion than are found in area V1 of cats/primates. Furthermore, we demonstrate for the first time that mice exhibit bistable visual perception of plaid stimuli, and that this depends, at least in part, on area V1 input. Finally, we suggest that the relative proportion of component-motionselective responses to pattern-motion-selective responses in mouse V1 may bias visual perception, as evidenced by changes in the direction of elicited optokinetic responses.

\section{Introduction}

A fundamental task faced by the visual system is the computation of global scene motion from the local motion of the parts of

\footnotetext{
Received Feb. 26, 2016; revised Sept. 1, 2016; accepted Sept. 21, 2016.

Author contributions: G.P. and S.M.S. designed research; G.P. and J.F.M. performed research; G.P. and J.F.M. analyzed data; G.P. and S.M.S. wrote the paper.

S.M.S. received support from a Howard Hughes Medical Institute Early Career Award, the March of Dimes Foundation, the Simons Foundation, and National Eye Institute Grant R01-EY-109272. We thank Ryan Ash for helpful comments and help with manuscript preparation; Sergey Torsky for excellent technical assistance; Tsai-Wen Chen, Dmitry Yatsenko, and Andreas Tolias for sharing MATLAB code for the motion correction algorithm and the field-ofview segmentation algorithm for GCaMP6s timecourses extraction; and Catheryn Hughes for help with histological preparations.

The authors declare no competing financial interests.

Correspondence should be addressed to either of the following: Ganna Palagina, Jamaica Plain Veterans Administration Hospital, Boston VA Research Institute, Boston, Massachussets 02130, E-mail: anna.palagina@gmail.com or Stelios M. Smirnakis, Brigham and Women's Hospital and Jamaica Plain Veterans Administration Hospital, Harvard Medical School, Boston, Massachusetts 02115, E-mail: smsmirnakis@partners.org.
}

the scene (Hildreth and Koch, 1987; Albright and Stoner, 1995). Symmetric additive plaid stimuli have been used in cats and primates to characterize the stage at which visual processing sensitivity to complex motion arises, identifying two distinct populations of neurons (Movshon et al., 1985; Albright and Stoner, 1995). The first population, exemplified by units in cat and primate V1, is orientation and direction selective (Movshon et al., 1985; Gizzi et al., 1990) but is not sensitive to complex motion arising from the interaction of different parts of the scene moving in different directions. The second population of neurons is capable of combining information about the motion of different "elementary" components of the scene. Such neurons are essentially absent from anesthetized primate and cat area V1 
(see Figs. 4C, 5C), but start appearing in higher-order thalamic nuclei and extrastriate areas of higher mammals, with the largest populations occurring in areas engaged in visuomotor control and integration [V5/middle temporal area (MT) and medial superior temporal area (MST)] in primates (see Figs. $4 D, 5 D$; Movshon et al., 1985; Rodman and Albright, 1989; Gizzi et al., 1990; Albright and Stoner, 1995; Scannell et al., 1996; Merabet et al., 1998; Khawaja et al., 2009). So, essentially, in higher mammals, pattern-motion (PM) selectivity is generated in extrastriate areas, while V1 neurons are chiefly capable of componentmotion-selective responses (but see Guo et al., 2004; and see Discussion).

In rodents and lower vertebrates, however, the computations of complex object motion may begin at earlier stages than secondary cortical areas, as early as in retina (Olveczky et al., 2003; Baccus et al., 2008). Compared with cat and primate, mouse V1 is anatomically small, allowing single cells to access information from a larger part of the visual field (Van den Bergh et al., 2010). In principle, this makes global motion computations possible at the first stage of cortical visual processing (Gao et al., 2010). A different scheme of visual motion processing may then occur in mouse visual cortex, where some V1 cells act as complex motion integration units rather than as the narrow orientation and direction-of-motion filters prevalent in cat and monkey V1. To explore this possibility, we measured the response properties of mouse V1 pyramidal neurons to type I symmetric additive plaid patterns (Adelson and Movshon, 1982; Movshon et al., 1985; Albright and Stoner, 1995). Type I symmetric plaid patterns are composed of two component gratings whose directions of motion are symmetric relative to the motion of the global pattern. The angle between component gratings is the plaid cross-angle (CA; Adelson and Movshon, 1982; Movshon et al., 1985; Albright and Stoner, 1995; see Fig. 2A). Cells that respond to the global drift of the intersection pattern (pattern-motion selective) are expected to have similar direction-of-motion tuning curves for both gratings and plaid stimuli (see Fig. $2 B$, left). In contrast, cells sensitive to the motion of individual component gratings [component-motion (CM) selective] have bilobed tuning curves when tested with plaids (see Fig. $2 B$, right), since they respond vigorously each time a component grating moves in their preferred direction (Movshon et al., 1985; Albright and Stoner, 1995).

\section{Materials and Methods}

Methods summary. We used C57BL/6 mice, expressing Td-Tomato in Dlx5/6-positive interneurons (Madisen et al., 2010; Miyoshi et al., 2010) in an Oregon-Green-Bapta-1-AM (OGB) set of experiments, and C57BL/6 mice expressing GCaMP6s in cortical neurons for an interlayer comparison set of experiments (Tronche et al., 1999; Madisen et al., 2015). All animals were male. Windows, $3 \mathrm{~mm}$ in diameter, were placed over V1. OGB with SR-101 (Stosiek et al., 2003) were injected 2.5-3 mm lateral from midline and $1-1.5 \mathrm{~mm}$ anterior to the transverse sinus (Fig. $1 A$ ). Layer $2 / 3$ (L2/3) cells $120-200 \mu \mathrm{m}$ below the pia were imaged at 3.5-7.5 Hz using a Prairie Ultima-IV two-photon microscope fed by a Chameleon Ti:sapphire laser [ $820 \mathrm{~nm}, 20 \times, 0.95$ numerical aperture (NA) objective, Olympus; maximum intensity at sample, $<50 \mathrm{~mW}$ ). Isoflurane $0.6 \%$ was used for anesthesia. We presented visual stimuli monocularly on an LCD monitor (Dell) covering $60^{\circ} \times 80^{\circ}$ of the contralateral visual field. Visual stimuli consisted of drifting square-wave gratings $\left(2 \mathrm{~Hz}, 0.05\right.$ cycles $\left.^{\circ}\right)$ and additive plaid patterns, which were constructed by summing two component gratings at $60^{\circ}$ or $120^{\circ} \mathrm{CA}$ and normalizing for contrast (Smith et al., 2005). Stimulus presentation trials lasted $5 \mathrm{~s}$ ( $2 \mathrm{~s}$, stimulation; $3 \mathrm{~s}$, uniform illumination; 180-360 trials were acquired per stimulus type; grating, $60^{\circ} \mathrm{CA}$ plaid or $120^{\circ} \mathrm{CA}$ plaid). The mean luminance was constant throughout. We covered the nonstimu- lated eye with black foil. Image analysis used custom MATLAB routines and ImageJ (Abràmoff et al., 2004). Following xy-plane motion correction, we defined cell regions of interest (ROIs) and expressed calcium signals as relative fluorescence changes $(\mathrm{dF} / \mathrm{F})$ corresponding to mean fluorescence from all pixels inside specific ROIs. Responses were measured either as the integral of calcium events with amplitude $>3$ SDs above noise, or as relative spike rates after deconvolution (Vogelstein et al., 2010). Either choice produced similar tuning curves (Fig. 1D, E; see Fig. 3). We calculated the direction selectivity index (DSI; Rochefort et al., 2011) for grating stimulation. To classify directionally selective (DSI, $>0.5$ ) cells as PM- or CM-selective, we used partial correlation analysis followed by the Fisher $z$-transform (Smith et al., 2005; see Figs. 4A, $B$, $5 A, B)$. Current-clamp recordings were obtained with a Heka EPC-10 USB amplifier following the study by Margrie et al. (2002). We recorded optokinetic responses to gratings and plaids in eight head-posted mice $\left(60^{\circ} \mathrm{CA}\right.$ plaid, $n=8 ; 120^{\circ} \mathrm{CA}$ plaid, $\left.n=8\right)$ with an infrared camera (model GC660, Allied Vision Technologies) and histogrammed the distribution of optokinetic nystagmus (OKN) directions.

Animals and surgery. All experimental procedures were performed in accordance with institutional and federal animal welfare guidelines, and were approved by the Baylor College of Medicine institutional animal care and use committee. For OGB experiments, we used C57BL/6 mice expressing Td-Tomato in Dlx5/6-positive interneurons (Madisen et al., 2010; Miyoshi et al., 2010). The mice were produced by crossing the Ai9 mice, carrying a targeted insertion into the Gt(ROSA)26Sor locus with a loxP-flanked STOP cassette preventing transcription of a CAG promoter-driven red fluorescent protein variant ( $t$ d-tomato; Madisen et al., 2010), and Dlx5/6-Cre mice, carrying a Cre-recombinase gene, expressed under the $D l x 5 / 6$ promoter (The Jackson Laboratory; Miyoshi et al., 2010). Offspring mice, carrying both the flox-stopped $t d$-tomato and Cre, express Td-Tomato in $\sim 65 \%$ of interneurons originating from the lateral geniculate eminence.

Mice for GCaMP6s experiments were produced by crossing Ai96 GCaMP6s reporter mice (Madisen et al., 2015) to Nestin-Cre mice, expressing Cre-recombinase under nestin promoter (Tronche et al., 1999); both mice were from The Jackson Laboratory. Offspring mice, carrying both the flox-stopped GCaMP6s and Cre, express GCaMP6s in cortical and peripheral neurons. Mice were reared in a $12 \mathrm{~h}$ dark/light cycle until $2-3$ months of age and subsequently were used for recordings. During surgery, mice where anesthetized with $2 \%$ isoflurane, which was delivered in pure oxygen via tubing near the nose of the animal. Local anesthesia with lidocaine $(2 \%)$ was given under the skin and on the skull. We placed a $3 \mathrm{~mm}$ round craniotomy above V1 (Fig. 1A), and, for OGB experiments, pressure injected $1 \mathrm{~mm}$ OGB with $100 \mu \mathrm{M}$ SR-101 dissolved in Pluronic via a glass pipette $200 \mu \mathrm{m}$ below the dura (Stosiek et al., 2003). All injection sites were located $2.5-3 \mathrm{~mm}$ lateral from midline and $1-1.5 \mathrm{~mm}$ frontal to the transverse sinus, placing them squarely in the central area V1 (Wang and Burkhalter, 2007; Marshel et al., 2011; Fig. $1 A)$. After injection, we fixed a glass coverslip above V1 with Vetbond glue. We kept eyes moisturized using a topical eye ointment (polydimethylsiloxane-200, Sigma-Aldrich). One hour after injection, we reduced the isoflurane level to $0.6 \%$ and performed two-photon calcium imaging.

Visual stimulation for the two-photon experiments. We constructed visual stimuli using the MATLAB Psychophysics Toolbox (www. psychtoolbox.org). We used drifting square-wave gratings with a temporal frequency of $2 \mathrm{~Hz}$ and a spatial frequency of 0.05 cycles $/{ }^{\circ}$. These parameters were selected because they were previously demonstrated to be optimal for the larger portion of neurons in rodent V1 (Ohki et al., 2005; Niell and Stryker, 2008; Gao et al., 2010). Additive plaid patterns were constructed by summing up component gratings of $50 \%$ contrast (Smith et al., 2005). We used plaid patterns for which the cross-angle between gratings was $60^{\circ}$ or $120^{\circ}$. Each visual presentation trial lasted $5 \mathrm{~s}$ : $2 \mathrm{~s}$ of visual stimulus presentation, followed by $3 \mathrm{~s}$ of spatially uniform illumination. We kept mean luminance constant throughout both the background and the stimulation periods. We presented stimuli on a flat LCD monitor (Dell), which was located $27 \mathrm{~cm}$ from the mouse eye, and covering $60^{\circ} \times 80^{\circ}$ in the contralateral monocular visual field. Presenta- 
A

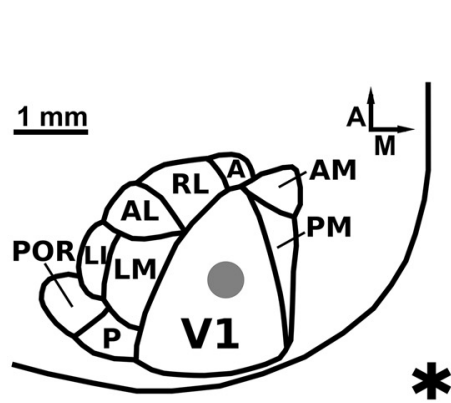

B

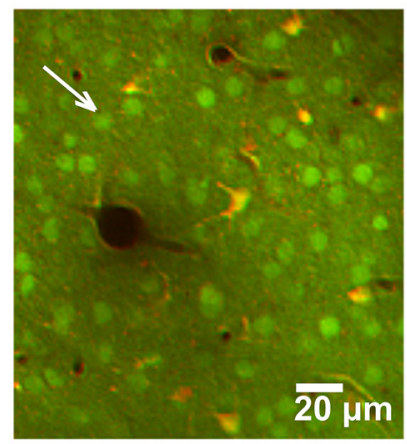

C

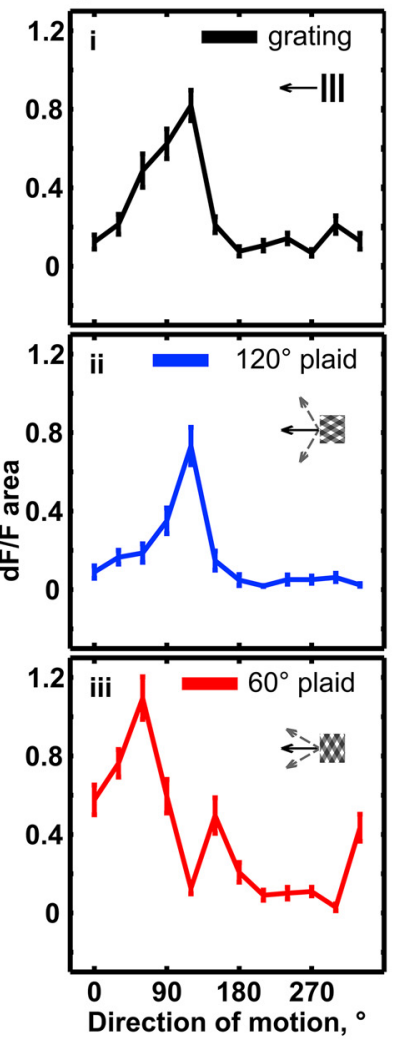

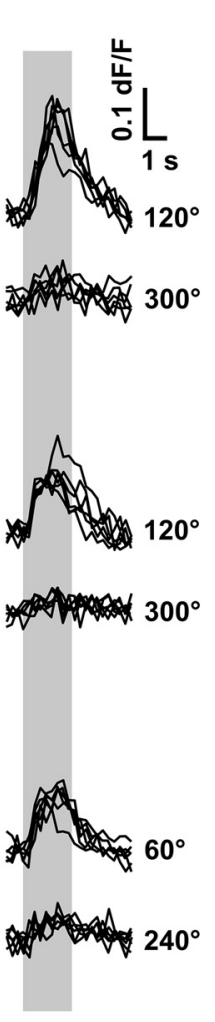

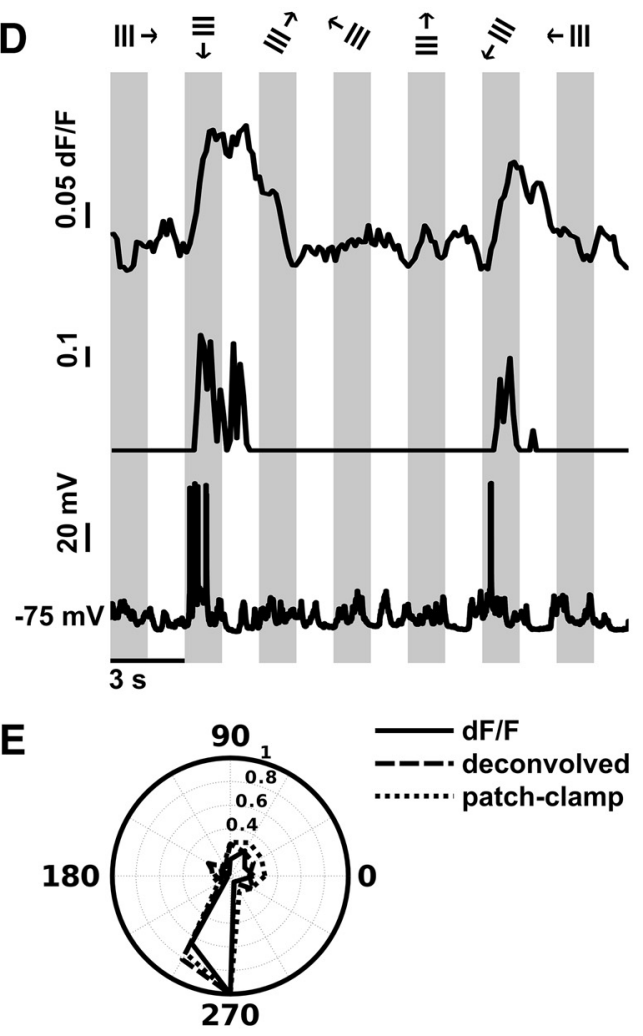

Figure 1. Direction selectivity of pyramidal cells in mouse V1.A, Position of OGB injection and imaged area in the V1 of the left hemisphere. Typical range of dye injections is denoted by gray circle (2.5-3 mm lateral from midline, 1-1.5 mm anterior to transverse sinus). Position and average layout of area V1 and belt visual areas are adapted from Wang and Burkhalter (2007) and Marshel et al. (2011). A, Anterior; M, medial. We targeted injections to central V1. Star denotes the position of midline (medial) and the location of transverse sinus (posterior to V1). Scale bar, 1 mm. $\boldsymbol{B}$, Typical in vivo two-photon image of L2/3 neurons in area V1. Green, OGB-filled cells; orange, astrocytes and Td-Tomato-expressing interneurons. White arrow denotes the cell body of the neuron from $\boldsymbol{C}$. $\boldsymbol{C}$, Example tuning curves (left) and responses (right) of the directionally selective pyramidal cell in response to drifting gratings and plaid patterns. We obtained tuning curves shown by calculating the mean area under the calcium transients evoked by stimuli with different directions of motion. Gray box in right panels signifies the stimulus presentation time. Ci, Tuning curve elicited by moving gratings. Right, Single-trial responses to the preferred stimulus ( $120^{\circ}$, top curves), and to a stimulus moving in the opposite direction ( $300^{\circ}$, bottom curves). Cii, Tuning curve (blue) elicited by a moving plaid with $120^{\circ} \mathrm{CA}$. Right, Single-trial responses to the preferred plaid stimulus ( $\left.120^{\circ}\right)$, and a plaid stimulus moving in the opposite direction ( $300^{\circ}$, bottom curves). Ciii, Tuning curve (red) elicited by a moving plaid with $60^{\circ} \mathrm{CA}$. Right, Single-trial responses to the preferred plaid stimulus ( $60^{\circ}$, top curves), and stimulus moving in the opposite direction ( $240^{\circ}$, bottom curves). Inset calibration: 0.1 (10\%) dF/F, 1 s. Error bars: mean \pm SEM. D, Deconvolution of calcium dF/F signals to compute relative firing rates (Vogelstein et al., 2010 ). Top, dF/F computed from 0GB-1 signals. Middle, Corresponding deconvolved (Vogelstein et al., 2010) normalized mean firing rates. Bottom, corresponding current-clamp recording of spiking activity of the patched neuron. $\boldsymbol{E}$, Tuning curves normalized to peak response, obtained from dF/F data (solid black line), current-clamp data (dotted black line) and deconvolved data (broken black line) from the cell in $\boldsymbol{D}$. Note the high degree of correspondence between the tuning curves of each measure. The high correspondence between the 0BG-based tuning curves and action potential-based tuning curves is expected, as calcium signals do not reach saturation for the range of recorded action potentials, which were generated in response to the stimuli that we used.

tion was monocular. We covered the nonstimulated eye with black foil during the experiment.

Two-photon imaging. We used a Prairie Ultima-IV two-photon microscope with custom modifications, fed by a Chameleon Ti:sapphire Ultra-II laser and equipped with two Hamamatsu photomultiplier tubes. PrairieView software (version 4.1.1.4) was used to control the laser and collect images (Prairie Technologies). We imaged cells $120-200 \mu \mathrm{m}$ below the pia, in layer $2 / 3$ of mouse V1. The laser was set at a wavelength of $820 \mathrm{~nm}$. At this wavelength, red fluorescing cells were either Td-Tomatoexpressing interneurons or SR-101-stained astrocytes. We selected cells that did not display red fluorescence and, therefore, were identified as pyramidal neurons. We selected an ROI containing 50-320 cells for imaging and acquired images using a $20 \times$ objective lens $(0.95 \mathrm{NA}$ waterimmersion, Olympus) at acquisition speeds ranging from $\sim 3.5$ to $7.5 \mathrm{~Hz}$, depending on ROI size. For GCaMP6s imaging, we used a 16× waterimmersion objective, the laser wavelength was set to $920 \mathrm{~nm}$, and the acquisition speed was set at $6.5-7.5 \mathrm{~Hz}$. Typically, we collected six to eight 15 -min-long movies from each region of interest. Each movie was followed by a rest period of 15-30 min, during which the monitor remained at uniform illumination to maintain mean light level adaptation.
Patch-clamp recordings. Whole-cell and loose-patch recordings were obtained with a Heka EPC-10 USB amplifier in current-clamp mode using standard techniques (Margrie et al., 2002). Briefly, 6-8 M $\Omega$ glass pipettes filled with an intracellular solution (in mM: $105 \mathrm{~K}$-gluconate, $30 \mathrm{KCl}, 10$ HEPES, 10 phosphocreatine, 4 ATP-Mg, and 0.3 GTP, adjusted to 290 mOsm and $\mathrm{pH} 7.3$ with $\mathrm{KOH}$, containing $10 \mu \mathrm{m}$ Alexa Fluor-594 or tetramethylrhodamine dextran; Invitrogen) were advanced under two-photon visual guidance, initially with $\sim 100$ mbar pressure, then $\sim 40$ mbar when $\sim 50$ $\mu \mathrm{m}$ under the dura. We reduced pressure to $\sim 20$ mbar when approaching a cell. Once resistance increased to $\sim 150 \%$ of the initial value, laser scanning was stopped and up to 200 mbar negative pressure was applied, until the resistance increased up to $200 \mathrm{M} \Omega$. When successful, a gigaohm seal was typically formed within $2 \mathrm{~min}$. The pipette was retracted carefully by a few micrometers to avoid penetration of the interior compartments of the cell during break-in. Then $\sim 200 \mathrm{~ms}$ pulses of negative pressure (starting at $-10 \mathrm{psi}$ and increasing gradually) were applied via a Picospritzer with a vacuum module until the patch of membrane was broken. Fast pipette capacitance was neutralized before break-in, and slow capacitance was neutralized afterward.

Calcium imaging data analysis. We performed image analysis off-line in several steps, using custom-written MATLAB routines and ImageJ 
A

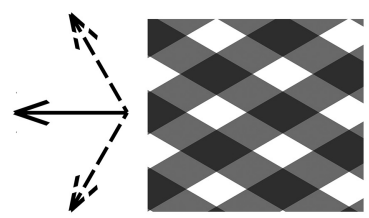

B

PM-selective

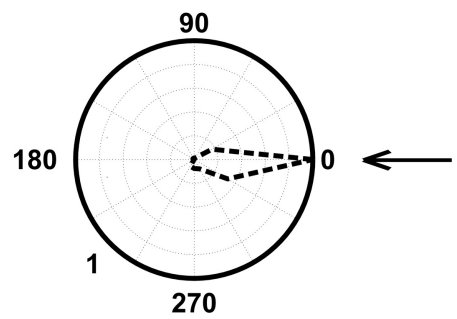

grating

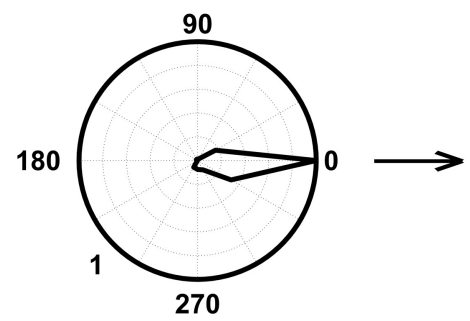

CM-selective

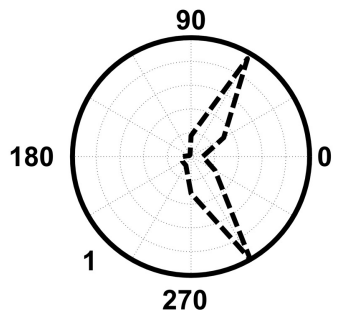

Figure 2. Stimuli and partial correlation analysis. A, Symmetric (type I) additive square-wave plaids (Adelson and Movshon, 1982; Albright and Stoner, 1995; Guo et al., 2004; Smith et al., 2005). The direction of motion of the global plaid pattern (solid arrow) bisects the angle between the directions of motion of the individual component gratings (dotted arrows). $\boldsymbol{B}$, Partial correlation model. Middle, Tuning curve elicited by moving gratings (solid black line). Left, Predicted tuning curve for the $120^{\circ} \mathrm{CA}$ plaid in case of PM-selectivity (dotted black line). Right, Predicted tuning curve for the $120^{\circ} \mathrm{CA}$ plaid in case of component-motion selectivity (CM-selectivity, dotted black line).

(Abràmoff et al., 2004). For OGB-1 data, we first applied motion correction to remove slow drifts on the $x-y$-plane, using cross-correlation between subsequent frames of the movies, containing red (Td-Tomatoand SR-101-based) fluorescent signals. After motion correction, we used ImageJ software to draw the ROIs of cells around cell body centers, staying 1-2 pixels from the margin of a cell to avoid contamination from neuropil signals. We then averaged the signals of cell ROI pixels and converted them into dF/F. For GCaMP6s data, we used custom-written MATLAB software obtained from Tsai-Wen Chen (Howard Hughes Medical Institute, Janelia Research Campus, Ashburn, VA) to perform image segmentation and extract signals from doughnut-shaped cell bodies frame by frame (since GCaMP6s is excluded from the nucleus of the cells, at low expression levels the cell bodies appear doughnut shaped). We also used this software to extract signals from dendritic sections. Cell and dendritic ROI transients were accepted as firing events when their amplitude exceeded 2 SDs of prestimulus activity, which was calculated over a period of $1 \mathrm{~s}$ immediately before the stimulus onset. We estimated the response of each cell to the stimulus by the integral of the $\mathrm{dF} / \mathrm{F}$ calcium transients evoked during the stimulus presentation period (from 0 to $2 \mathrm{~s}$ after stimulus onset) and averaged across similar stimulus trials (dF/F area; mean of 15-30 trials). In a separate analysis, we deconvolved $\mathrm{dF} / \mathrm{F}$ signal time courses using the algorithm of Vogelstein et al. (2010), thereby converting the calcium signal from each neuron to inferred, relative spike rates. These were then compared between visual stimulation and uniform illumination periods. Similar tuning curves were obtained when using either $\mathrm{dF} / \mathrm{F}$ signal or the deconvolved data to estimate the response of the neurons (Fig. 1D, E; see Fig. 3).

Direction selectivity index. We evaluated the selectivity of each cell for the direction of motion using the DSI, as follows:

$$
D S I=\left(D_{\text {preferred }}-D_{\text {opposite }}\right) /\left(D_{\text {preferred }}+D_{\text {opposite }}\right),
$$

where $D_{\text {preferred }}$ is the response to motion in the preferred direction of the cell, and $D_{\text {opposite }}$ is the response to motion in the opposite direction. Highly selective cells have a DSI value near 1, while a 3:1 response difference would result in a DSI value of 0.5 . Neurons with DSI of $>0.5$ when stimulated with moving gratings and responsive to at least one of the plaids were selected for partial correlation analysis. Tuning width was estimated by fitting the dominant peak with a Gaussian and estimating the half-width of the fitted curve at half-height.

Partial correlation analysis for classifying cells as PM-selective versus $C M$-selective. Cells that were responsive for at least one of the plaids and showed direction selectivity for the drifting gratings were subjected to partial correlation analysis (Smith et al., 2005) to determine whether their responses were more consistent with CM-selectivity or with PMselectivity. Following the findings of Smith et al. (2005), we used the grating tuning curve of each cell to construct two extreme-case predictions for the response of the cell to a drifting plaid, as follows: (1) a prediction corresponding to an exclusively CM-selective cell; and (2) a prediction corresponding to an exclusively PM-selective cell (Fig. 2B). The prediction for PM-selectivity corresponds to the tuning curve ob- tained with gratings (Fig. 2B, left and middle). The prediction for CMselectivity is built by averaging the tuning curve of the cell for grating rotated left and right by the offset angle of the plaid components (Fig. 2B, right). Next, we calculated the linear Pearson correlation coefficient between the actual tuning curve of each cell obtained with a plaid and the PM- and CM-selective tuning curve predictions for the cell $\left(r_{p}\right.$ and $r_{c}$, respectively) for the same plaid. Then we calculated partial correlation coefficients (PM-selective response $\left(R_{p}\right)$ and CM-selective response $\left(R_{c}\right)$, respectively) by adjusting for the correlation between predictions, as follows:

$$
\begin{aligned}
& R_{c}=\left(r_{c}-r_{p} r_{\mathrm{pc}}\right) / \sqrt{\left(1-r_{p}^{2}\right)\left(1-r_{\mathrm{pc}}^{2}\right)}, \\
& R_{p}=\left(r_{p}-r_{c} r_{\mathrm{pc}}\right) / \sqrt{\left(1-r_{c}^{2}\right)\left(1-r_{\mathrm{pc}}^{2}\right)},
\end{aligned}
$$

where $r_{c}$ is the linear Pearson correlation coefficient between the CMselective prediction and the actual plaid tuning function, $r_{p}$ is the linear Pearson correlation coefficient between the PM-selective prediction and the actual plaid tuning function, and $r_{\mathrm{pc}}$ is the linear Pearson correlation between the PM- and CM-selective predictions. To rate the selectivity for pattern versus component motion of each cell, we applied a version of the Fisher $z$-transform (Smith et al., 2005) to calculate the associated $z$-scores, as follows:

$$
\begin{aligned}
& Z_{c}=(\sqrt{(n-3)}) * 0.5 \ln *\left(\left(1+R_{c}\right) /\left(1-R_{c}\right)\right), \\
& Z_{p}=(\sqrt{(n-3)}) * 0.5 \ln *\left(\left(1+R_{p}\right) /\left(1-R_{p}\right)\right),
\end{aligned}
$$

where $n$ (12 in our case) is the number of points in the correlation (i.e., the number of different directions used to measure direction-of-motion tuning curves), and $(n-3)$ is the number of degrees of freedom. We adopted a $95 \%$ confidence threshold, corresponding to a $z$-score difference of 1.645 as a measure of significant difference between pattern $z$-score $\left(Z_{p}\right)$ and component $z$-score $\left(Z_{c}\right)$ values. If the $Z_{p}$ value of a cell was greater than $Z_{c}$ value of the cell or 0 (whichever is greater) by 1.645 , we classified the response of the cell as PM-selective. Analogously, if the $Z_{c}$ value of a cell was greater than the $Z_{p}$ value or 0 (whichever is greater) by 1.645 , the response of the cell was classified as CM-selective. Cells that did not meet these criteria remained unclassified. To compare with prior studies in cats and primates (Gizzi et al., 1990; Movshon and Newsome, 1996; Smith et al., 2005), we repeated the classification with the $90 \%$ confidence threshold (significant $z$-score difference, 1.28) used there. This threshold did not affect the general conclusions of our study.

Unimodal unclassified cells. To identify unimodal unclassified cells for further analysis, we selected cells that satisfied all of the following criteria: (1) the cell showed direction selectivity for drifting gratings (single peak tuning curve; DSI $=>0.5$; as defined in Materials and Methods, Direction selectivity index) and also generated above-noise responses for the plaids of the specific cross-angle $\left(60^{\circ}\right.$ and/or $\left.120^{\circ}\right)$; (2) the responses for the plaids are either single peaked or double peaked with opposite peaks, and the monodirectional cells were evaluated by plaid DSI (pDSI), which 
is computed in the same way as the direction-selectivity index for the gratings, as follows:

$$
\operatorname{pDSI}=\left(D_{\text {preferred }}-D_{\text {opposite }}\right) /\left(D_{\text {preferred }}+D_{\text {opposite }}\right),
$$

where $D_{\text {preferred }}$ is the response for motion to the preferred plaid direction of the cell, and $D_{\text {opposite }}$ is the response for motion to the opposite direction. Highly selective cells have a pDSI value near 1 , while a 3:1 response difference would result in a pDSI value of 0.5 .

Bidirectional responses to plaids were evaluated by the bi-DSI (bDSI), which is computed the same way that the orientation selectivity index is computed for the gratings, as follows:

$$
\mathrm{bDSI}=\left(D_{\text {peak }}-D_{\text {orth }}\right) /\left(D_{\text {peak }}+D_{\text {orth }}\right),
$$

where $D_{\text {peak }}$ is the direction axis along which peak responses occur, while $D_{\text {orth }}$ is the direction axis orthogonal to the peak response axis.

If the cell had both bDSI and pDSI values of $>0.5$, it was accepted as monodirectional, and if cell had only a bDSI value of $>0.5$, it was accepted as bidirectional.

Next, we looked at how the peak or peaks of the tuning curve of the cell for the plaid related to the tuning curve peak of the grating. A monodirectional cell was considered to be pattern-motion aligned if its tuning curve peak of the plaid exactly coincided or was exactly opposite to the tuning curve peak of the grating. A bidirectional cell was considered to be pattern-motion aligned if either one of its peaks for the tuning curve of the plaid was aligned with the peak of the grating. A cell was considered to be component-motion aligned if its tuning curve for the plaid had a peak rotated in relation to the grating tuning curve peak by half of the cross-angle of the plaid (i.e., pointing along one of the plaid components).

Optokinetic nystagmus. We recorded nystagmoid responses to drifting gratings and plaids in $8 \mathrm{C} 57 \mathrm{BL} / 6$ head-posted mice. The stimulus was presented on three screens, positioned around the mouse to cover $\sim 270^{\circ}$ of the visual field of the mouse (see Fig. $8 A, B$ ). The center of each screen was located at $\sim 27 \mathrm{~cm}$ from the mouse. Stimulus parameters were identical to the ones used for two-photon experiments. We used an infrared camera (model GC660, Allied Vision Technologies) to record the movements of the right eye at $60 \mathrm{~Hz}$. We analyzed 10- to 20-min-long movies off-line with custom MATLAB code to determine the position (center of mass) of the pupil relative to the position (center of mass) of the reflection of the infrared light source on the surface of the cornea (see Fig. 8C). Optokinetic eye movement (EM) is composed of smooth pursuit following stimulus drift, followed by rapid saccade in the direction opposite to the direction of global stimulus drift. This pattern of movements [slow pursuit phase plus rapid saccade phase repeats as long as the stimulus (drifting grating or plaid) is present]. For relatively small EMs, the distance between the center of the pupil and the corneal reflection is proportional to the frontal projection of the angular deflection of the eye (Sakatani and Isa, 2004; Cahill and Nathans, 2008). We analyzed both vertical and horizontal EM components. Periods containing eye-blink artifacts were removed. EMs consisting of slow pursuit movement in the direction of the drift of the global stimulus $\pm 89^{\circ}$ and preceded by a saccade in a direction opposite to the drift of the global stimulus $\pm 89^{\circ}$ were selected for further analysis. We applied linear fit to the slowpursuit phase of each EM, and EMs with $r^{2}>0.5$ were accepted for further analysis. We determined the direction of each accepted EM by comparing the amplitude of horizontal and vertical saccade projections of components. We compensated for the inherent difference in gain between vertical and horizontal OKN by measuring the relative mean saccade amplitude for horizontal versus vertical drifting gratings. Typically, the vertical OKN amplitudes were, on average, smaller than the horizontal OKN amplitudes by a factor of $\sim 1.5$. Then we used the ratio of horizontal to vertical saccade amplitude to adjust the amplitude of the vertical component of OKN elicited by plaid stimuli. We then histogrammed the directions of EMs from $\left[-89^{\circ}, 89^{\circ}\right]$, where $0^{\circ}$ corresponds to the horizontal direction (which is also the direction of the drift of the global stimulus; see Fig. 8J). For the plaid-induced OKN, we classified each EM as component or pattern aligned. For this, we first determined the width of the distribution of EM angles evoked by horizontally drifting gratings. We used $1 \mathrm{SD}$ from the mean (typically located at 0 ) as the threshold for pattern-aligned EM angles. Thus, any EM whose angle exceeded this threshold was classified as component aligned, while EMs with angles inside the $[-$ STD, + STD $]$ interval are pattern aligned. To study the dynamics of OKN alternation between following the global pattern drift or component motion, we cut out the periods of the stable OKN (at least three saccade-pursuit pairs, occurring without break between the pairs; e.g., saccadic movement is immediately followed by the pursuit phase of the next pair). In each period, we determined the duration that was occupied by the persistent tracking of global pattern versus the duration that was occupied by the persistent tracking of component gratings before the alternation occurred, or the OKN period ended. Then we determined the durations of "coherent" and "transparent" OKN phases and their fraction out of the total duration of OKN.

Optokinetic nystagmus under V1 lesions. Unilateral V1 lesions were made in seven Dlx 5/6-Cre mice, expressing Td-Tomato in a subset of interneurons. The lesions (lesion size: coronal plane, $0.8-1.8 \mathrm{~mm}$; sagittal plane, $1.5-1.8 \mathrm{~mm}$; located approximately in the center of the V1) were induced by photocoagulation under visual two-photon guidance, using a laser with a wavelength of $810 \mathrm{~nm}$. The location and extent of the lesions within the V1 were verified by Nissl staining of brain sections (60 $\mu \mathrm{m}$ thick) after the experiment in three animals (see Fig. 9A,B). Optokinetic responses were measured before and after the lesion in both the contralateral (lesion-affected) and ipsilateral eye (see Fig. 9C). Ipsilateral eye measurements served as an internal control for the contralateral eye. $\mathrm{OKN}$ in mice is asymmetric, and responses are driven by the eye receiving the temporonasal stimulation. Because of this, we adjusted the global direction of the stimulus so that the recorded eye was always receiving temporonasal stimulation (see Fig. 9C). Four animals received monocular stimulation, with stimulus running on two screens covering $180^{\circ}$ of visual space (see Fig. 9C). Three animals received binocular stimulation, as shown in Figure $8 A$. The monocular and the binocular results were pooled together for statistical assessment, as the general direction of change did not differ between the two conditions.

Statistical tests. For comparisons of the ratio of PM-selective/CMselective responses and the fraction of component EMS, we used the two-tailed paired $t$ test and the Wilcoxon rank-sum test to account for the small sample size (six to eight animals). A paired Wilcoxon rank-sum test was also applied to assess the changes in OKN properties after the $\mathrm{V} 1$ lesion. To estimate the goodness of fit for the gamma distribution fitting of OKN bistability periods, we used a $\chi^{2}$ test. The statistical significance of cell classification as pattern-motion selective or component-motion selective was ascertained by applying bootstrapping to the existing tuning curves. To do this, we constructed 1000-2000 surrogate tuning curve pairs (grating-plaid) by randomly drawing and averaging $10-15$ singletrial responses from the pool of single-trial responses for each condition and for each direction drift (two conditions, 12 directions/condition, 15-30 trials/direction). The resulting surrogate tuning curve pairs were then assigned a $z$-score difference value by partial correlation analysis and Fisher transform, just like real tuning curve pairs (see Materials and Methods, Partial correlation analysis). This resulted in the distribution of the $z$-score difference values for each cell (1000-2000 values/distribution). We then determined whether the real $z$-score value of each cell fell within the 0.95 confidence interval of the distribution. If the real $z$-score value of the cell was found to be outside of the 0.95 confidence interval, such a cell was removed from analysis. In addition, we determined whether a significant number of $z$-scores in the bootstrapped distribution of the cell $(>5 \%)$ fell into the category opposite to the one assigned at the classification of real tuning curves (i.e., if the cell was classified as PM-selective, we determined whether $>5 \%$ of the bootstrapped $z$-score differences were in fact indicative of CM-selectivity; $z<-1.28$ ). Cells meeting this criterion were also removed from the analysis.

\section{Results}

Pyramidal neurons show direction-selective responses for both drifting gratings and two-dimensional moving plaids We tested 1119 pyramidal neurons from six animals in L2/3 of mouse V1 using square-wave gratings and plaid stimuli with $60^{\circ}$ 
and $120^{\circ} \mathrm{CAs}$. We used standard stereotaxic coordinates to place cranial windows over mouse V1 (Fig. 1A) and used two-photon imaging with $\mathrm{OGB}$ to record neuronal responses under light $(0.6 \%)$ isoflurane anesthesia (see Materials and Methods; Fig. $1 B)$. A total of $60.6 \%$ of recorded pyramidal cells (678) were visually responsive [i.e., generated above-noise ( $>3$ SDs) responses for at least one visual stimulus]. Figure $1 C$ illustrates a representative example of stimulus-driven $\mathrm{dF} / \mathrm{F}$ calcium responses, and tuning curves elicited with gratings (black), $60^{\circ}$ CA plaids (red), and $120^{\circ} \mathrm{CA}$ plaids (blue). Relative firing rates were extracted from the calcium signal using a well validated deconvolution algorithm by Vogelstein et al. (2010; Fig. $1 D)$. Figure $1 E$ and Figure 3 illustrate the excellent correspondence between tuning functions calculated from $\mathrm{dF} / \mathrm{F}$ calcium data, deconvolved firing rates, and actual firing rates recorded via whole-cell patch clamp (Fig. $1 E$ ). This is expected, since the OGB-based calcium signal does not saturate for the range of action potential responses observed in our experiments. For the analysis in the rest of the manuscript, tuning functions are calculated from deconvolved calcium data (Vogelstein et al., 2010). Using the $\mathrm{dF} / \mathrm{F}$ calcium data to measure tuning functions (Fig. $3 A, C$ ) does not change the results presented.

Three hundred and seventeen pyramidal neurons $(\sim 47 \%$ of all visually responsive pyramidal cells, and $28 \%$ of all recorded cells) showed direction of motion selectivity (DSI, $>0.5$ ) in response to drifting gratings (Andermann et al., 2011; Rochefort et al., 2011). The median width of direction tuning was estimated at $28^{\circ}$, which is in line with previous data on the direction selectivity of $\mathrm{V} 1$ units from the mouse (Niell and Stryker, 2008; see Materials and Methods). Of those direction-selective cells, $235(\sim 74 \%)$ were also responsive to drifting plaid stimuli (the $60^{\circ}$ plaid, the $120^{\circ} \mathrm{CA}$ plaid, or both). We classified these neurons as CM-selective versus PMselective, depending on how they responded to plaid stimuli, following the study by Smith et al. (2005). Figure 3, $A$ and $B$, illustrates the tuning functions of four CM-selective example neurons, calculated from dF/F (Fig. $3 A$ ) and deconvolved calcium data (Fig. $3 B$ ). Neurons 1 and 2 showed CM-selective responses when tested with the $60^{\circ} \mathrm{CA}$ plaid, while neurons 3 and 4 showed CM-selective responses when tested with the $120^{\circ} \mathrm{CA}$ plaid. These neurons showed unimodal direction-ofmotion tuning for grating stimuli (Fig. $3 A, B$, black curves) but bimodal tuning for plaids $\left(60^{\circ}\right.$, red; $120^{\circ}$, blue), with peaks offset by $\sim 30^{\circ}$ for the $60^{\circ} \mathrm{CA}$ plaid (neurons 1 and 2) and by $\sim 60^{\circ}$ for the $120^{\circ} \mathrm{CA}$ plaid (neurons 3 and 4 ). They are, therefore, selective for the direction of motion of component gratings, but not for the direction of motion of the resulting plaid texture (Figs. $3 A, B, 4 A, B$, CM-selective neurons). Neurons 5-8 (Fig. $3 C, D$ ) had matching single peaks under either the plaid or the grating condition and were classified as PMselective (Figs. $3 C, D, 4 A, B$, PM-selective neurons). In addition, mouse $\mathrm{V} 1$ contains a substantial percentage of cells that are not responsive to gratings or show responses that are not tuned to gratings, which do generate directionally tuned responses for full-field plaids. Approximately 32\% of visually responsive pyramidal cells (217 of 678) showed such properties. This finding stands in contrast with cats or primates, for which we can find no such reports in the literature describing V1. However, a small percentage of cells with similar properties (directionally tuned for the plaid patterns, but poorly responsive to gratings) were reported in marmoset MT (Solomon et al., 2011).

\section{Pattern- and component-motion-selective responses in mouse V1 differ from cat and primate V1}

To classify the responses of neurons as CM- or PM-selective, we computed the partial correlation coefficients of the plaid tuning function of each cell with the prediction for $r_{p}$ or $r_{c}$ (Fig. 2), taking into account the correlation between the two predictions $\left(r_{\mathrm{pc}}\right.$; see Materials and Methods). Using the Fisher $z$-transform, we then converted the correlation measures $\left(R_{p}, R_{c}\right)$ into $z$-scores $\left(Z_{p}, Z_{c}\right)$ to assess significance (see Materials and Methods; Smith et al., 2005 ). Figure $4 A$ shows population results obtained with the $60^{\circ}$ CA plaid stimulus condition (Fig. $5 A$, corresponding $z$-score plot). The solid black line corresponds to confidence level $p=$ 0.95. At this confidence level, $12.1 \pm 2.5 \%$ of direction-selective $\mathrm{L} 2 / 3 \mathrm{~V} 1$ cells generated PM-selective responses and $10.0 \pm 2.0 \%$ generated CM-selective responses in the $60^{\circ} \mathrm{CA}$ plaid stimulus condition (mean \pm SEM; error computed across animals, $n=6$ animals). A lower percentage of PM-selective cells ( $4.4 \pm 0.5 \%$ ) was detected under the $120^{\circ} \mathrm{CA}$ plaid stimulus condition (Figs. $4 B, 5 B)$, while the percentage of CM-selective cells increased slightly $(12.8 \pm 2.6 \%)$. To compare our results with the literature, we also used the less selective criterion $(p=0.9)$ adopted by prior investigators (Gizzi et al., 1990; Smith et al., 2005). Using this criterion, $14.8 \pm 3.6 \%$ of direction-of-motion-selective mouse V1 neurons were classified as PM-selective, and $13.6 \pm 2.8 \%$ as $\mathrm{CM}$-selective under the $60^{\circ} \mathrm{CA}$ plaid condition (mean $\pm \mathrm{SEM}$; $n=6$ animals; Fig. $6 \mathrm{~A}, \mathrm{~B}$ ). For the $120^{\circ} \mathrm{CA}$ plaid, we found $5.7 \pm$ $1.5 \%$ of PM-selective neurons and $19.9 \pm 3.2 \%$ CM-selective neurons, respectively (mean \pm SEM; $n=6$ animals; Fig. $6 A, B$ ). These observations suggest that mouse V1 behaves differently from primate and cat V1, which seem to contain almost exclusively CM-selective neurons (Figs. 4C, 5C, 6A, E; Table 1). Under the same classification criterion, $\sim 84 \%$ of direction-of-motionselective units recorded in cat and primate V1 under anesthesia are CM-selective (mean across seven studies using plaids with cross-angles ranging from $90^{\circ}$ to $150^{\circ}$; Table 1; Fig. $6 A$ ). In contrast, the maximum average number of component neurons we obtained in the mouse V1 was $\sim 20 \%$ under the $120^{\circ}$ cross-angle plaid (the maximum percentage of component cells obtained with the $120^{\circ}$ plaid in an individual animal was $30 \%$ ). The opposite trend is true for PM-selective units: essentially no PMselective units are found in most cat and primate studies $(\sim 1.3 \%$, average over seven studies; a total of $3 \mathrm{PM}$-selective neurons were identified of 229 neurons in seven studies; Table 1; Fig. 6B,E), whereas mouse V1 on average has $\sim 6-15 \%$ PM-selective neurons, depending on the cross-angle of the plaid (Figs. $4 A, B$, $5 A, B)$.

The difference is made immediately evident if one considers the distribution of responses in the partial correlation space or $z$-score space (Figs. 4,5 ). Note that there is a markedly different spread of neuronal responses elicited from mouse V1 (Figs. $4 A, B$, $5 A, B)$ compared with the $\mathrm{V} 1$ of cats or primates (Figs. $4 C, 5 C$ ). In fact, the distribution of partial correlations and associated $z$-scores is more similar between mouse $\mathrm{V} 1$ and cat/primate extrastriate cortex than cat/primate V1. Note that we mention this to stress the difference in area V1 complex motion processing across the species considered, and not to claim that motion processing in mouse $\mathrm{V} 1$ is equivalent to motion processing in cat/ primate extrastriate cortex. In fact, the percentages of PM- and CM-selective units are lower in mouse V1 compared with cat/ primate extrastriate areas.

One concern that arises, especially in the case of $60^{\circ}$ crossangle plaids, is whether PM versus CM classification can be performed accurately, given the width of the tuning functions. To 
A

\section{Component motion-selective}

dF/F

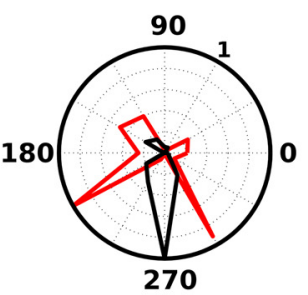

neuron 1

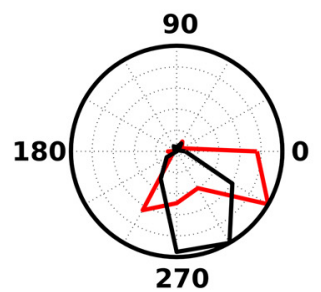

neuron 2
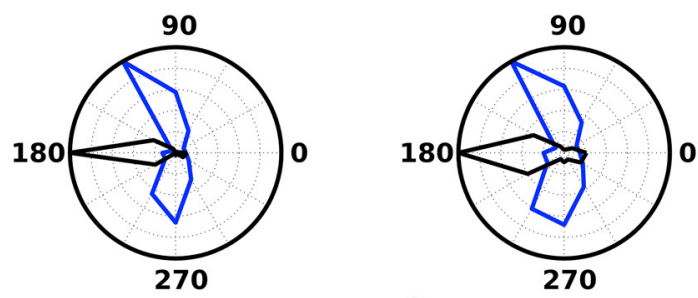

neuron 3

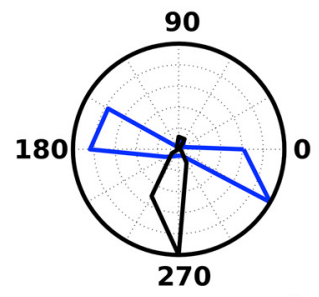

neuron 4

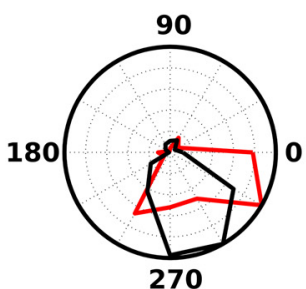

Deconvolved

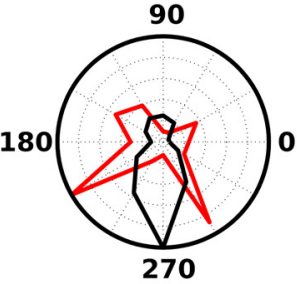

270

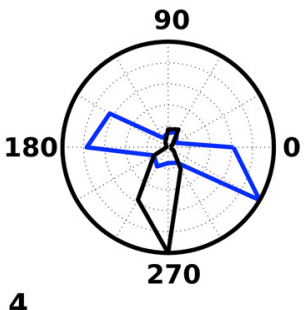

C

Pattern motion-selective

dF/F

Deconvolved
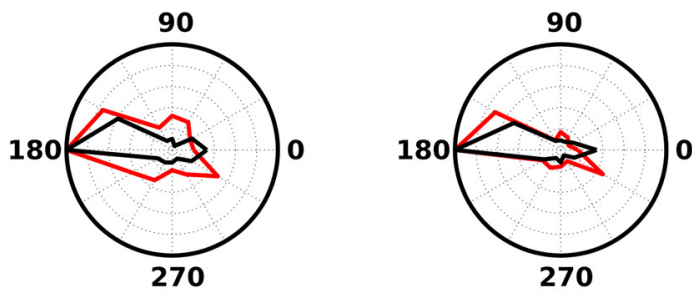

neuron 5



neuron 6
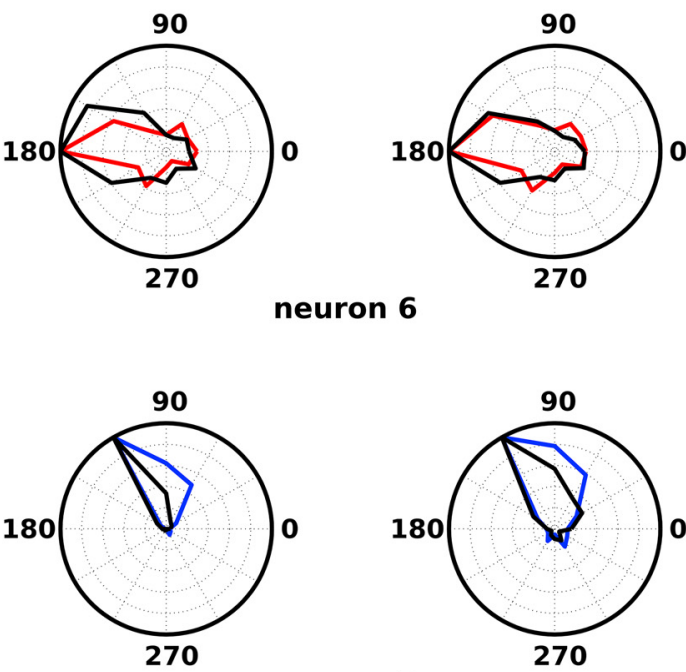

neuron 7
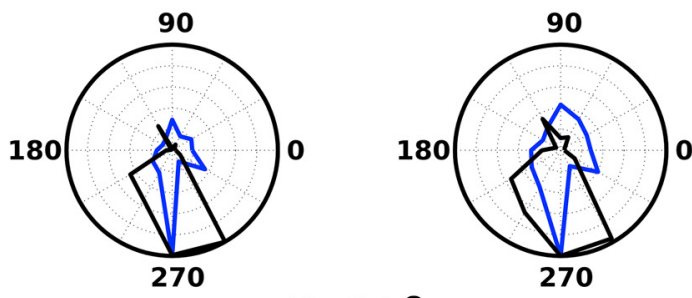

neuron 8

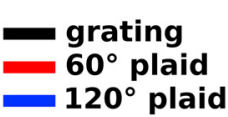

Figure 3. Examples of component-motion-selective and pattern-motion-selective pyramidal cells: $\mathrm{dF} / \mathrm{F}$ data vs deconvolved calcium data. $\boldsymbol{A}, \boldsymbol{B}, \mathrm{CM}$-selective cells. $\boldsymbol{C}, \boldsymbol{D}, \mathrm{PM}$-selective cells. $\boldsymbol{A}, \boldsymbol{C}$, Normalized tuning curves, obtained from dF/F calcium data. $\boldsymbol{B}, \boldsymbol{D}$, Normalized tuning curves, obtained from deconvolved calcium data. Note the close correspondence between tuning curves obtained from dF/F data and deconvolved data. Black, Tuning curves obtained with moving gratings; red, tuning curves obtained with $60^{\circ} \mathrm{CA} \mathrm{plaids;} \mathrm{blue,} \mathrm{tuning} \mathrm{curves} \mathrm{obtained} \mathrm{with} 120^{\circ} \mathrm{CA}$ plaids. Neurons $1-4(A, B)$ are CM-selective. Note that the bilobed tuning curves generated by plaids have peaks offset from the direction of pattern motion by approximately half of the $C A$ of the plaid $\left(30^{\circ}\right.$ for neurons 1 and 2; $60^{\circ}$ for neurons 3 and 4$)$. Neurons $5-8(\boldsymbol{C}, \boldsymbol{D})$ are PM-selective and have unimodal direction of motion-tuning functions that match closely for gratings and for plaids.

ensure that our results are not artifactual, we used a bootstrap strategy and confirmed that we analyzed neurons for whom classification remained consistent across different subgroups of trials (see Materials and Methods). In any event, it is important to note that our basic conclusions hold true, even if we consider only results obtained with $120^{\circ}$ cross-angle plaids (Fig. 6, summary).

Another possible confound arises because our data were collected using square-wave plaids and gratings versus the sine wave gratings used in the majority of prior studies. It has been argued before that components with different frequencies in these stimuli may alter cell characterization as CM- versus PM-selective. To ensure that this did not factor into the reported differences, we performed additional measurements for the dataset based on sine-wave gratings and $120^{\circ} \mathrm{CA}$ plaids (Figs. $4 B, 5 B, 60$ directionselective plaid-responsive from two animals are marked with gray dots), using the same procedures as for the square-wave data. In 
A

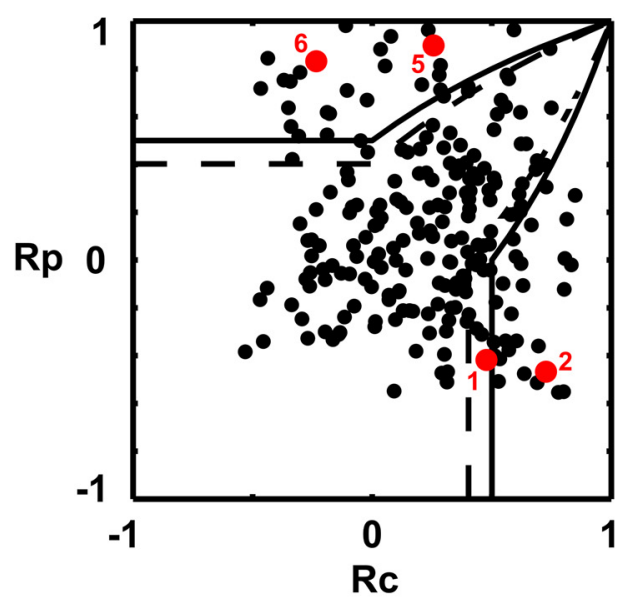

C V1 (cat, monkey)

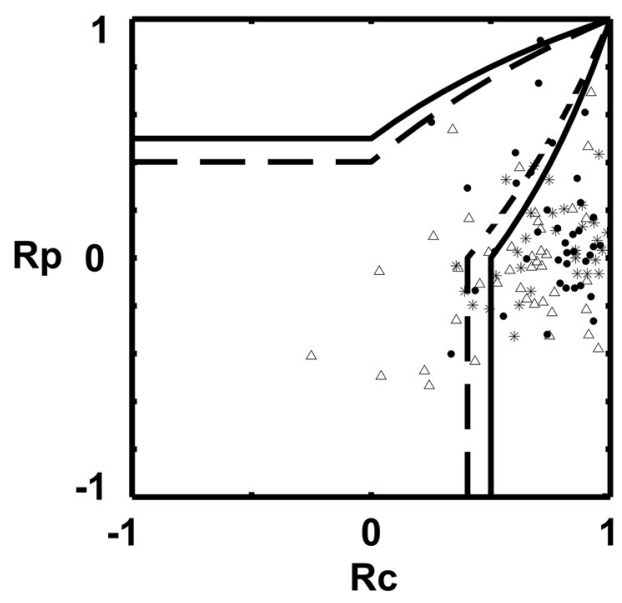

$\begin{array}{ll}\Delta & \text { V1 (Guo et al., 2004) } \\ * & \text { V1 (Gizzi et al., 1990) } \\ - & \text { V1 (Movshon \& Newsome, 1996) }\end{array}$
B $120^{\circ}$ CA plaid

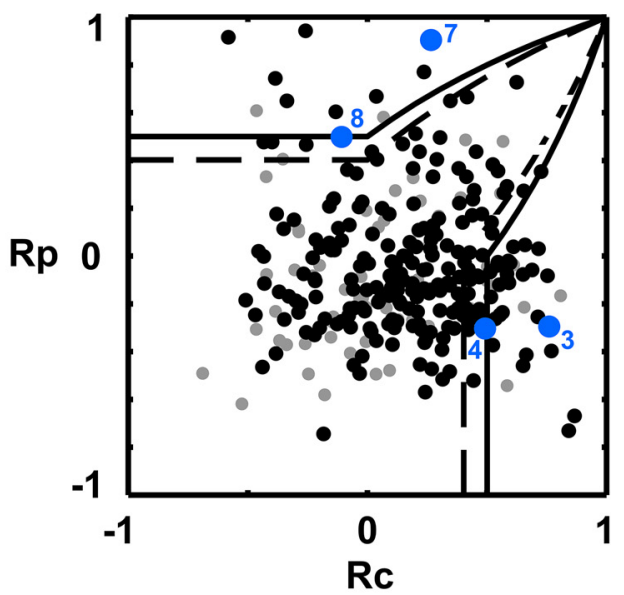

D Extrastriate

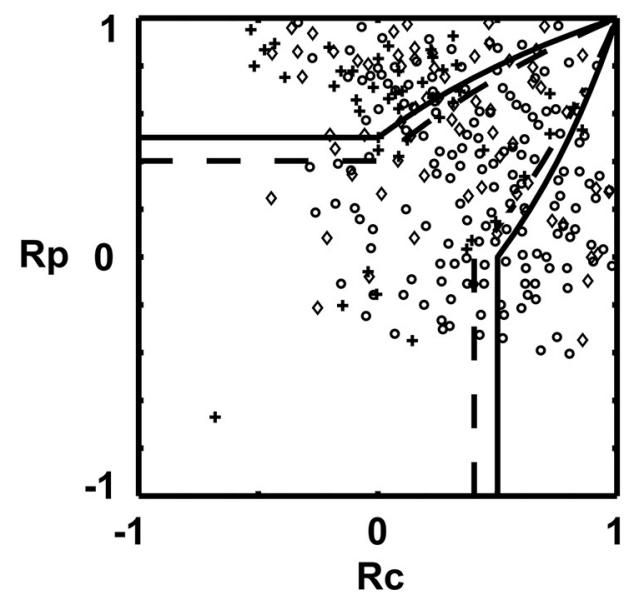

$\diamond \quad$ LP - Pulvinar (Merabet et al., 1998)

- $\quad$ MT (Movshon et al., 1985)

$+\quad$ AEV (Scanell et al., 1996)

Figure 4. Component- and pattern-motion selectivity population results. $A-D$, Scatter plot of component and pattern partial correlation coefficients calculated for each directionally selective L2/3 pyramidal neuron recorded in mouse V1 $(\boldsymbol{A}, \boldsymbol{B})$, and previous studies in cat/primate V1 $(\boldsymbol{C})$, and higher visual areas $(\boldsymbol{D})$, following the study by $S$ mith et al. (2005). The $x$-axis plots the $R_{c}$ value for each cell (see Materials and Methods). The $y$-axis plots the $R_{p}$ value. Black line boundaries demarcate statistical significance levels calculated from the Fisher transform (see Materials and Methods; Smith et al., 2005): solid black line, $p=0.95$; broken black line, $p=0.9$. The $p=0.9$ value has generally been used by previous investigators (Movshon and Newsome, 1996; Smith et al., 2005). $A$, Results for the $60^{\circ} \mathrm{CA}$ plaid. Red dots denote the positions of neurons 1 and 2 (CM-selective responses), and 5 and 6 (PM-selective responses) from Figure 3 . Black dots, Data obtained using square-wave gratings and plaids (six animals). $\boldsymbol{B}$, Results for the $120^{\circ} \mathrm{CA}$ plaid. Blue dots, Neurons 3 and 4 (CM-selective responses), and neurons 7 and 8 (PM-selective responses) from Figure 3; black dots, data obtained using square-wave gratings and plaids (six animals); gray dots, data obtained using sine-wave gratings and plaids (two animals). C, Literature results from cat and monkey V1 under anesthesia. Data were digitized from the studies by Gizzi et al. (1990), Movshon and Newsome (1996), and Guo et al. (2004). Black filled circles, Monkey V1 (Movshon and Newsome, 1996); stars, cat V1 (Gizzi et al., 1990); triangles, monkey V1, layers 4 and 6 (Guo et al., 2004). Unlike mouse V1 and extrastriate areas of cats and primates, primate and cat V1 under anesthesia contains a large majority of (M-selective neurons with only a small minority of unclassified cells and virtually no PM-selective cells. $\boldsymbol{D}$, Aggregate population plot of direction-selective cells from cat and monkey extrastriate visual cortical areas and higher-order thalamic nuclei derived from the literature. Data were digitized from the studies by Movshon et al. (1985), Scannell et al. (1996), and Merabet et al. (1998). Open circles, Monkey V5/MT (Movshon et al., 1985); crosses, cat anterior ectosylvian visual area (AEV; Scannell et al., 1996); and rhomboids, cat lateral posterior nucleus of thalamus (LP)-pulvinar complex (Merabet et al., 1998). Note that the shape of the distribution we observe in $\boldsymbol{A}$ and $\boldsymbol{B}$ from mouse $\mathbf{V} 1$ is similar to the distributions observed in the extrastriate areas of cats and primates.

this dataset, $\sim 5 \%$ of cells showed PM-selectivity, and $\sim 13 \%$ were classified as CM-selective. Again, a major portion of the direction-selective cells $(\sim 82 \%)$ could not be classified. The point spread of both $z$-scores and $R$ values essentially corresponded to the respective spreads for the square-wave data (Figs. $4 B, 5 B)$. We conclude that using sine-wave versus square-wave stimuli does not alter our basic conclusions, and both classes of stimuli are similarly capable of eliciting CM- and PM-selective responses from mouse $\mathrm{V} 1$ neurons.

One important factor that can potentially affect the representation of CM- and PM-selective responses in visual cortex is recording depth (Movshon et al., 1985). In monkeys, the majority of the data on PM- and CM-selectivity of V1 neurons comes from deep layers of V1 (layer 4, layer 5 and 6 border, and layer 6; 
A

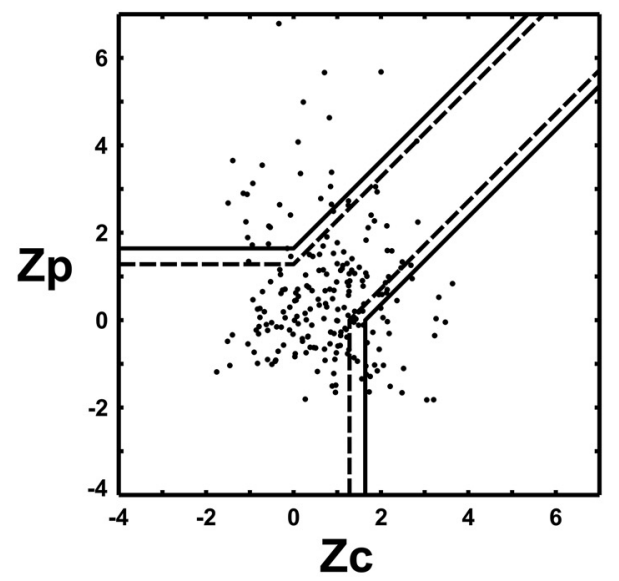

C

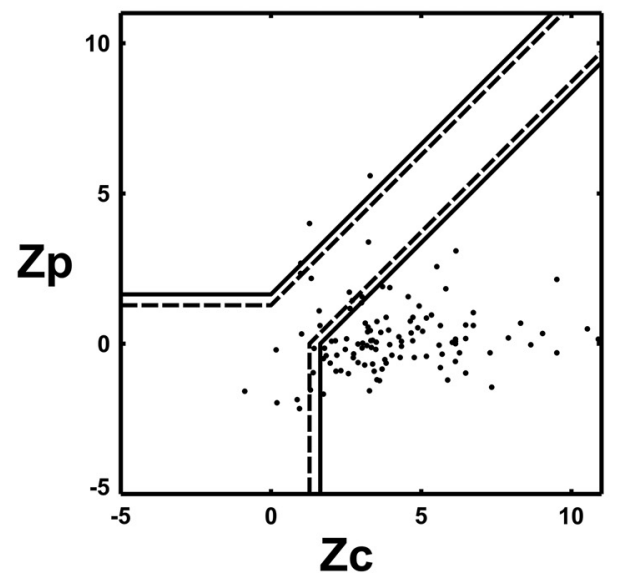

B

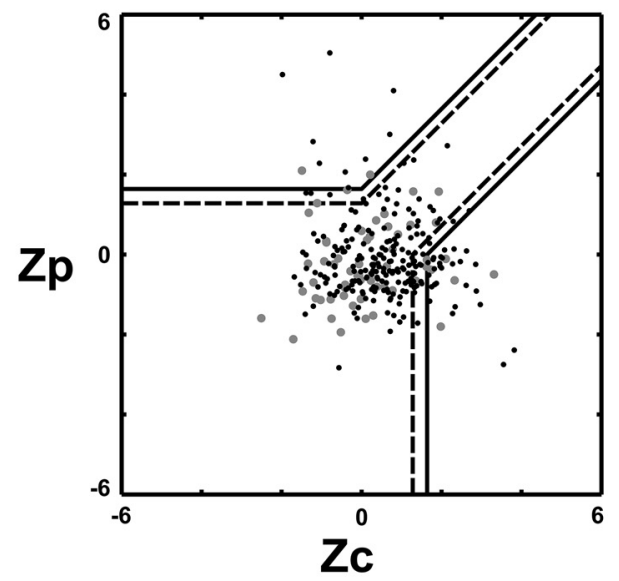

D

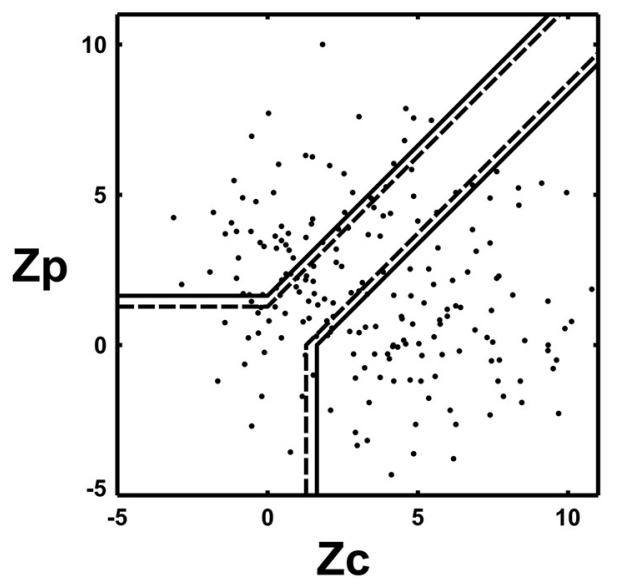

Figure 5. Component-motion and pattern-motion selectivity population results (z-scores). Scatter plot of component and pattern z-score coefficients calculated for each directionally selective L2/3 pyramidal neuron recorded in mouse V1. The $x$-axis plots the $Z_{c}$ value for each cell (see Materials and Methods). The $y$-axis displays the $Z_{p}$ value. Black line boundaries demarcate statistical significance levels calculated from the Fisher transform (see Materials and Methods; Smith et al., 2005): solid black line, $p=0.95 ;$ broken black line, $p=0.9$. The $p=0.9$ value has generally been used by previous investigators (Movshon and Newsome, 1996; Smith et al., 2005). A, Results from the $60^{\circ}$ CA plaid, 232 cells pooled from six animals. All data were obtained with square-wave gratings and plaids (black dots). The corresponding plot of partial correlation coefficients is found in Figure $4 A$. $B$, Results from the $120^{\circ}$ CA plaid. Data obtained with square-wave gratings and plaids are marked with black dots ( 225 cells pooled from six animals), sine-wave data are marked with gray dots ( 60 direction-selective cells pooled from two animals). The corresponding plot of partial correlation coefficients is found in Figure 4B. C, Literature results from cat and monkey V1 under anesthesia. Partial correlation data were digitized from the studies by Gizzi et al. (1990), Movshon and Newsome (1996), Guo et al. (2004), and Khawaja et al., 2009; and z-transform was applied to derive z-scores. Unlike mouse V1 and extrastriate areas of cats and primates, primate and cat V1 under anesthesia contains a large majority of CM-selective neurons with only a small minority of unclassified cells and only sporadic PM-selective cells. $D$, Aggregate population plot of directionselective cells from cat and monkey extrastriate visual cortical areas and higher-order thalamic nuclei derived from the literature (MT, LS, and LP-pulvinar complex). Partial correlation data were digitized from the studies by Movshon et al. (1985), Gizzi et al. (1990), and Merabet et al. (1998); and were z-transformed to obtain associated z-scores. Note that the population in area V1 behaves more like extrastriate cat and monkey populations than like primate V1. Both primate extrastriate areas and mouse V1 contain large populations of unclassified direction-selective cells (primate extrastriate areas, 41\%; mouse V1, 74\%), while primate V1 contains a very small percentage of unclassified cells ( 16\%) and most of the direction-selective primate V1 cells are CM-selective ( $\sim 84 \%$ ). Thus, the shape of the distribution we observe in $\boldsymbol{A}$ and $\boldsymbol{B}$ from mouse $\mathrm{V} 1$ is more similar to the distributions observed in the extrastriate areas of cats and primates in its spread. The primate V1 distribution, in contrast, is narrowly centered in the (M-selective area of the plot (C).

Movshon and Newsome, 1996; Guo et al., 2004). These studies in V1 found no apparent differences with respect to PM/CM selectivity in layers 4 through 6 , finding that the overwhelming majority of the cells were CM-selective. The study by Solomon et al. (2011), collecting MT neurons throughout cortical thickness from layer 2 to 6 , found no apparent functional difference between the layers in MT. Our OGB-1 data, on the other hand, come from layer $2 / 3$, because imaging deeper layers with OGB-1 and other injectable calcium dyes in deeper layers required high laser power levels, which can result in photodamage. However, recently it became possible to also image deeper layers of the cortex using transgenic mice whose pyramidal neurons express the more efficient calcium-sensitive dye GCaMP6s (Madisen et al., 2015). We crossed Ai96 GCaMP6s reporter mice with mice expressing Cre-recombinase under nestin promoter (Tronche et al., 1999; Madisen et al., 2015). The offspring mice express fluorophore GCaMP6s in all cortical neurons. We used the resulting mice, expressing GCaMP6s in cortical neurons, to record data from layer 4 neurons and compare them to layer $2 / 3$ neurons. We collected data from five layer 4 FOVs (four mice; depth, 360-460 $\mu \mathrm{m}$ below the pia; 190 direction-selective neurons) and four L2/3 FOVs (four mice; depth, 130-230 $\mu \mathrm{m} ; 236$ direction-selective neurons). Figure $7 A$ shows all direction-selective $\mathrm{L} 2 / 3$ neurons recorded with GCaMP6s, and Figure $7 B$ shows all recorded L4 direction-selective cells (black dots) plotted along the axes of component-motion and pattern-motion selectivity. The fraction 
A

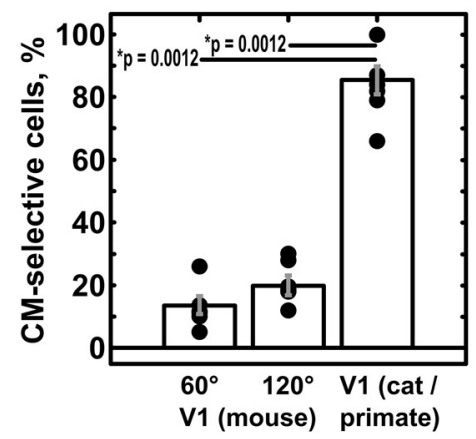

D

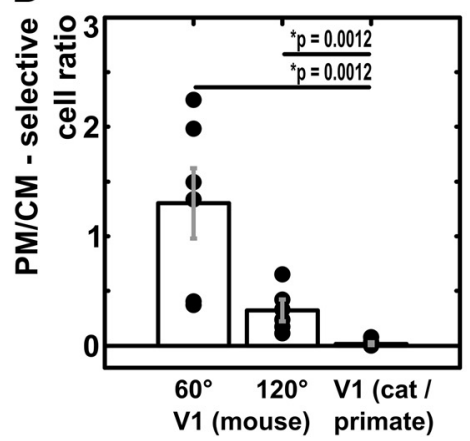

B

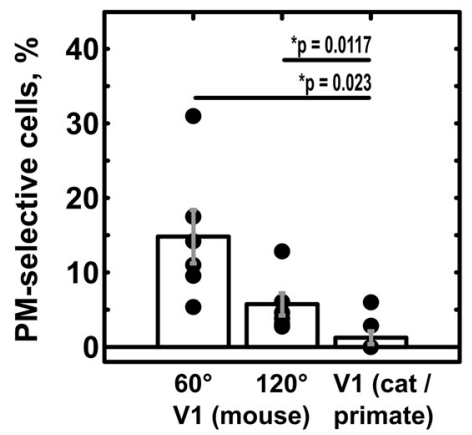

E

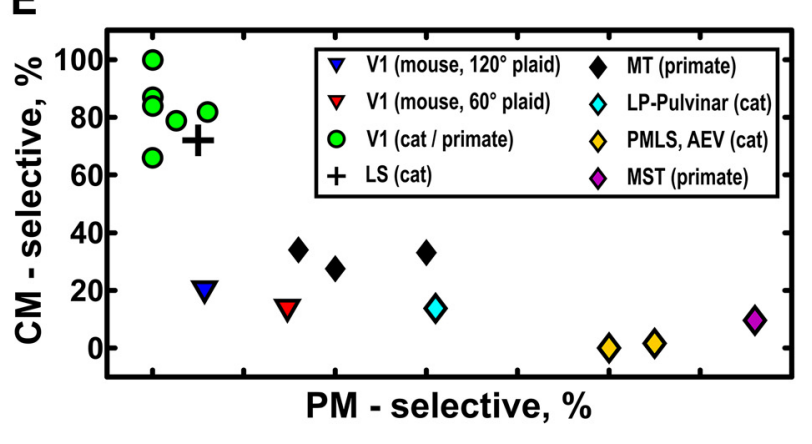

Figure 6. Comparison of complex motion properties of mouse V1 and visual areas of primates and cats. WRS, Wilcoxon rank-sum test; $60^{\circ}$, mouse area V1, $60^{\circ}$ plaid stimulation $(n=6$ animals); $120^{\circ}$, mouse area V1, $120^{\circ}$ plaid stimulation ( $n=6$ animals); V1 (cat/primate), primate or cat area V1 ( $n=7$ studies); LS, lateral suprasylvian area; PMLS, posteromedial lateral suprasylvian area; $\mathrm{AEV}$, anterior ectosylvian visual area. Error bars indicate the mean \pm SEM. Wilcoxon rank-sum test was used to access the difference between groups. $A$, The percentage of component-motionselective neurons in mouse V1 is considerably smaller than in primate and cat $\mathrm{V} 1[\mathrm{~V} 1(\mathrm{p})]$ for both $60^{\circ}$ and $120^{\circ}$ plaids $(p=0.0012$, WRS). $\boldsymbol{B}$, The percentage of neurons showing pattern-motion selectivity in mouse V1 is significantly larger than in primate V1 for both $120^{\circ}$ plaid $\left(p=0.0117\right.$, WRS) and $60^{\circ}$ plaid ( $p=0.0023$, WRS). C, Mouse V1 shows a high percentage of cells that are direction selective but cannot be classified as either CM- or PM-selective. The content of unclassified cells in mouse V1 is significantly higher than in primate and cat V1 $\left(120^{\circ}\right.$ plaid, $p=0.0012$, WRS; $60^{\circ}$ plaid, $p=0.0012$, WRS). D, The ratio between PM-selective and CM-selective responses in mouse V1 significantly decreases with increasing cross-angle of the plaid (120 vs $60^{\circ}$ plaid, $p=0.007$, WRS) and is significantly different form near-zero values, found in primate V1 (primate V1 vs mouse V1, $p=0.0012$, WRS; either cross-angle). $\boldsymbol{E}$, The relationship between PM-selective and CM-selective responses in mouse $\mathrm{V} 1\left(60^{\circ}\right.$ plaid, red triangles; $120^{\circ}$ plaid, blue triangles,), primate/cat V1 (green circles), thalamic nuclei (cyan rhomboids), and extrastriate visual areas of primates and cats (cross, cat area LS; yellow rhomboids, cat PMLS and AEV; black rhomboids, primate MT; violet rhomboids, primate MST). The ratio of PM- and CM-selective responses places mouse V1 in between primate/cat V1 and primate/cat extrastriate areas [apart from cat area LS (cross), which shows properties close to cat area V1].

Table 1. Breakdown of pattern-motion-selective and component-motion-selective units in cat and primate visual areas under anesthesia

\begin{tabular}{lccl}
\hline Area, species & $\begin{array}{l}\text { Pattern } \\
\text { cells, \% }\end{array}$ & $\begin{array}{l}\text { Component } \\
\text { cells, \% }\end{array}$ & References \\
\hline V1, cat & 0 & 87 & Gizzi et al. (1990) \\
V1, cat & 0 & 100 & Merabet et al. (1998) \\
V1, cat & 0 & 100 & Scannell et al. (1996) \\
V1 (layers 5, 6), monkey & 2.6 & 79 & Movshon and Newsome (1996) \\
V1, monkey & 6 & 82 & Khawaja et al. (2009) \\
V1 (layers 4C, 6), monkey & 0 & 66 & Guo et al. (2004) \\
V1 (cat and monkey) & 0 & 84 & Movshon et al. (1985) \\
Extrastriate & & & \\
$\quad$ LS, cat & 5 & 72.5 & Gizzi et al. (1990) \\
$\quad$ PMLS, cat & 50 & 0 & Merabet et al. (1998) \\
$\quad$ AEV, cat & 55 & 1.6 & Scannell et al. (1996) \\
Pulvinar-LP, cat & 31 & 13.70 & Merabet et al. (1998) \\
$\quad$ MT, monkey & 20 & 27.4 & Movshon and Newsome (1996) \\
$\quad$ MT, monkey & 30 & 33 & Rodman and Albright (1989) \\
MT, monkey & 16 & 34 & Movshon et al. (1985) \\
MST, monkey & 66 & 9.6 & Khawaja et al. (2009) \\
\hline
\end{tabular}

Generally, CM-selective units prevail in area $\mathrm{V} 1$ of anesthetized cats and monkeys. On average, $84 \%$ of directionally selective V1 cells are classified as CM-selective ( $66-100 \%$ depending on the study; see also Figs. 4C, 50 ). Note that essentially no PM-selective cells are identified in V1 of anesthetized cats and monkeys ( $\sim 1.3 \%$ on average; none in most studies). To be exact, 1 of $38 \mathrm{~V} 1$ units was found to be PM-selective in one study (Movshon and Newsome, 1996) and 2 of 33 in another (Khawaja et al., 2009), and none were found in the rest of the studies (Movshon et al., 1985; Gizzi et al., 1990; Scannell et al., 1996; Merabet et al., 1998; Guo et al., 2004). Extrastriate areas and high-order thalamic nuclei contain a variable percentage of PM-selective units (5-55\%) and CM-selective units ( $0-72.5 \%)$. LS, lateral suprasylvian area; PMLS, posteromedial lateral suprasylvian area; AEV, anterior ectosylvian area; LP, lateral posterior nucleus of thalamus. of L4 pattern-motion-selective cells was commensurate with those in L2/3 (L4-GCaMP6s: PM, 8\%; vs L2/3-GCaMP6s: PM, $\sim 10 \%$; L2/3-OGB-1: PM, 6\%). Layer 4 also has a smaller percentage of component-motion-selective cells than $\mathrm{L} 2 / 3$, whether measured with OGB-1 or GCaMP6s (L4-GCaMP6s: CM, 7\%; vs L2/3-GCaMP6s: CM, 17\%; L2/3-OGB-1: CM, 20\%). In conclusion, L4, like L2/3, has the following: (1) a much lower proportion of component-motion-selective cells than would be expected in cat or monkey V1 (7\% vs $84 \%)$; and (2) a higher proportion of pattern-motion-selective cells than would be expected in cat or monkey V1 ( $\sim 8 \%$ vs $\sim 1.3 \%$; Table 1 ; Fig. 6$)$.

To investigate the properties of cells in layers deeper than 4 , we analyzed calcium signals arising from apical dendrites that traversed the plane of the image in the lower half of layer 4 (in the three deepest FOVs; depth, $400-460 \mu \mathrm{m}$; located at deep layer 4 or layer 4 -layer 5 border) but did not connect to neuronal bodies located in the plane of imaging. These likely represent cross sections (2-4 $\mu \mathrm{m}$ in diameter) of apical dendrites arising in deeper layers (layers 5 and 6). Tuning properties of apical dendrites are thought to reflect closely those of the cell soma as they are dominated by back-propagating action potentials (Spruston, 2008). In total, we identified 52 such putative layer $5 / 6$ apical dendrites that showed direction-of-motion selectivity for gratings. They are plotted as gray dots in Figure $7 B$ and again mimic L2/3 data closely, as follows: $\sim 6 \%$ of putative L5/ 6 dendrites were PMselective and $\sim 15 \%$ were CM-selective (Fig. $7 B$, gray dots). This 
A

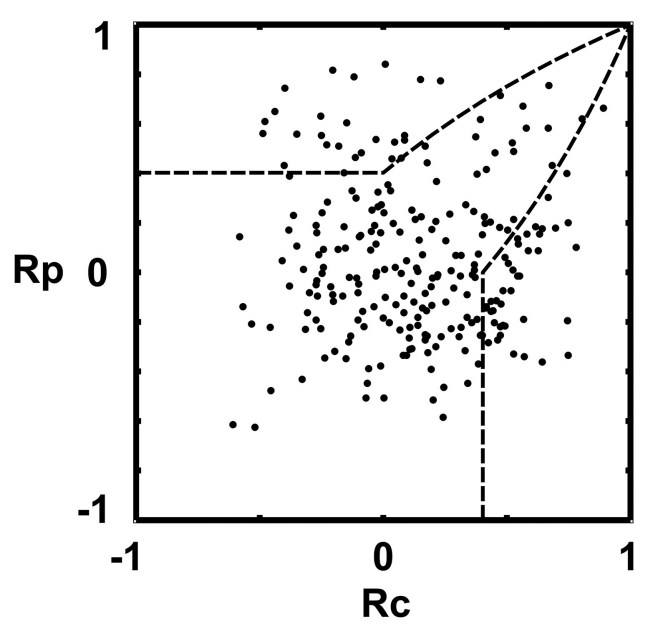

B

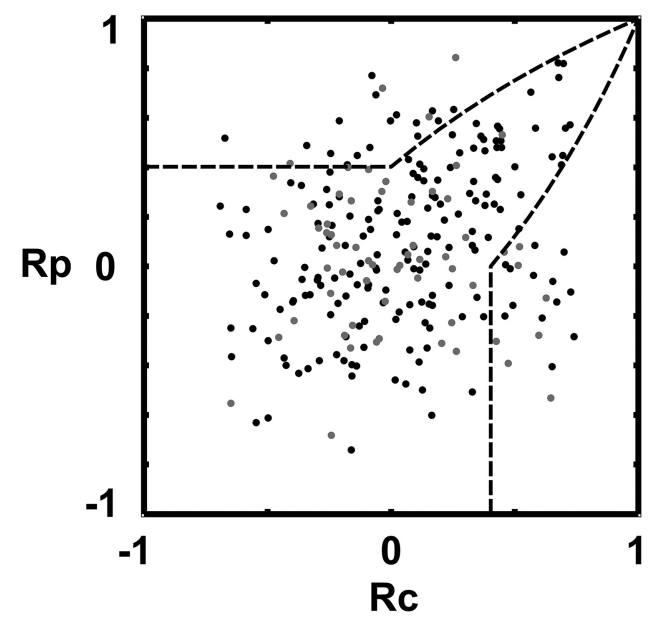

Figure 7. Component-motion and pattern-motion selectivity in layer $2 / 3$ vs layer 4 of mouse V1. $A, B$, Scatter plot of component and pattern partial correlation coefficients calculated for each direction-of-motion-selective pyramidal neuron recorded in layer $2 / 3$ of mouse V1 ( $\boldsymbol{A}$ ) vs layer 4 of mouse V1 (B), following the study by $S m i t h$ et al. (2005). The $x$-axis plots the $R_{c}$ value for each cell. The $y$-axis plots the $R_{p}$ value for each cell. Dotted black line boundaries demarcate statistical significance levels calculated from the Fisher transform (see Materials and Methods; Smith et al., 2005) at $p=0.9$. We use the $p=0.9$ value here, since this is the value that has generally been used by previous investigators (Movshon and Newsome, 1996; Smith et al., 2005). Direction-tuning data were obtained using the fluorophore GCaMP6s and a stimulation protocol similar to the one used for $0 \mathrm{~GB}-1$ data collection. $\boldsymbol{A}$, Results for the layer $2 / 3$ of $\mathrm{V} 1$, using $120^{\circ} \mathrm{CA}$ plaid (square-wavegratings). The shape of the $R_{p}-R_{c}$ distribution and the fraction of cells displaying pattern and component selectivity are essentially similar to the layer $2 / 3$ data obtained using $0 G B-1$ staining (Fig. $4 B$ ). Data were collected from four fields of view located at a depth of $130-230 \mu \mathrm{m}$. 0 f 236 cells that displayed direction-of-motion selectivity for the gratings, 23 cells were also pattern-motion selective ( 10\%) and 41 cells were also component-motion selective ( 17\%). B, Pattern-motion and component-motion selectivity in deep layers of mouse V1. Black filled dots, Results for layer 4 of mouse V1 obtained using the $120^{\circ}$ CA plaid. Data were collected from five fields of view located at a depth of between 360 and $460 \mu \mathrm{m}$. 0 f 190 cells that displayed direction- 0 -motion selectivity for the gratings, 16 cells were also pattern-motion selective ( $\sim 8 \%$ ), and 13 cells were component-motion selective ( $\sim 7 \%)$. Gray dots show results from 52 putative apical L5/6 dendrites recorded in L4 of mouse V1 (three FOVs, $400-460 \mu \mathrm{m}$ deep) using the $120^{\circ}$ (A plaid. Overall, the percentage of pattern-motion-selective responses detected in deeper layers (6-9\%) is commensurate to that seen in L2/3 (9\% in the GCaMP6s experiments; $6 \%$ in the $0 \mathrm{~GB}-1$ experiments reported in the text).

is very different than aggregate reports in cat/monkey V1, which find $\sim 84 \%$ of CM-selective cells and $\sim 1.3 \%$ of PM-selective cells (Table 1). In summary, we show that the fraction of cells classified as PM- or CM-selective does not differ drastically between L2/3 and deeper cortical layers in mouse V1. In fact, plotting the cells along the axes of CM-selectivity and PM-selectivity (Fig. 7) yields very similar distributions in L2/3 (Fig. 7A), L4 (Fig. 7B, black dots), and putative L5/6 (Fig. $7 B$, gray dots). These distributions are broad and contain a small percentage of pattern-motionselective cells $(6-10 \%)$, with the majority of cells $(\sim 73-85 \%)$ being unclassified.

\section{Unclassified direction-selective responses in layer $2 / 3$ of mouse V1}

In the mouse, unlike in cats or primates, the vast majority of cells ( $\sim 74 \%$ ) showing direction selectivity for drifting gratings generate responses for the plaid pattern that are not classifiable by the standard partial correlation analysis (Movshon and Newsome, 1996; Smith et al., 2005). However, these cells often have reasonable tuning functions when tested with the plaid stimuli. It is therefore interesting to examine the relationship between the peak of the tuning function elicited by plaids with that elicited by a drifting grating. First, we selected for analysis unclassified cells that have either (1) plaid-elicited tuning curves with a single peak (unidirection selective); or (2) plaid-elicited tuning curves that have two peaks in opposite directions (bidirection selective). We found that unidirection- and bidirection-selective cells constituted $\sim 60 \%$ of all unclassified cells ( 116 of 171 for the $60^{\circ} \mathrm{CA}$ plaid, and 96 of 167 for the $120^{\circ}$ CA plaid). We next checked whether the preferred direction of the cell, when tested with a plaid, coincided with the preferred direction when tested using the grating or was offset from it (in $30^{\circ}$ steps). Cells whose pre- ferred direction when tested with plaids coincided with that elicited by gratings (pattern-motion aligned) constituted $\sim 21 \%$ of the unclassified unimodal cells for the $60^{\circ} \mathrm{CA}$ plaid data versus $\sim 6 \%$ for the $120^{\circ} \mathrm{CA}$ plaid data (see Fig. $10 \mathrm{~A}$, neuron $1, B$, neuron 3 ). In contrast, $\sim 31 \%$ of the tuning curves of unclassified unimodal cells had peaks that coincided with the direction of drift of one of the two plaid components. Similar percentages of such component-sensitive cells were detected for the $60^{\circ}$ and the $120^{\circ} \mathrm{CA}$ conditions (see Fig. $10 A$, neuron $2, B$, neuron 4 ). Figure $10 C$ shows the distribution of the offsets between the preferred direction of tuning curves elicited by plaids versus the tuning curves elicited by a single grating. While the distribution for the $60^{\circ}$ plaid data was unimodal and centered at $0^{\circ}$ ( $\sim 21 \%$ cells having no offset; i.e., pattern-motion aligned), the distribution for the $120^{\circ}$ data had two peaks centering approximately at $\pm 60^{\circ}$ offsets (component-motion aligned), with only a small fraction $(\sim 6 \%)$ of unclassified cells having no offset. As expected, the ratio of pattern-motion-aligned responses to component-motion-aligned responses was shifted in favor of componentmotion sensitivity with increasing plaid cross-angle (see Fig. 10D). Overall, $\sim 52 \%$ of all unclassified cells show sensitivity for either pattern or component motion in the sense described above. These results suggest that even though unclassified cells have reduced selectivity for component versus pattern motion on a cell-by-cell basis, they may still contribute to motion processing and motion-based perceptual phenomena, like bistable perception, at the level of population responses.

\section{Origins of pattern-motion selectivity in mouse V1}

Existing models of pattern-motion selectivity in MT (Rust et al., 2006) assume that pattern-motion-selective units pool the outputs of narrowly tuned component-motion-selective cells whose direction of motion preferences are spread over a wide 
range of directions. Indeed, it was shown that the main source of such component-motion-selective units is the deep layers of area V1 (Movshon and Newsome, 1996). Pattern-motion-selective cells in mouse area V1 could similarly obtain their properties from local V1 component-selective and unclassified directionselective units. Alternatively, they could inherit their direction selectivity from subcortical targets, such as the pathway described by Cruz-Martin et al. (2014) originating in direction-selective retinal ganglion cells (Cruz-Martin et al., 2014) and supplying the direction information into the top layers of V1 through the orientation- and direction-selective units found in a mouse LGN shell (Piscopo et al., 2013; Marshel et al., 2011), bypassing layer 4. If the PM-selective cells in mouse V1 inherited their properties from local V1 direction-selective neurons, or LGN directionselective neurons via a process analogous to the monkey MT pooling of V1 inputs as described in cascade models (Rust et al., 2006), one would expect them to show broader direction-tuning bandwidth for gratings compared with component and unclassified cells in V1, strong opponent motion inhibition, and crossangle invariance of PM-selectivity (Rust et al., 2006; Solomon et al., 2011). Our experiments were not optimally designed to measure motion opponency. However, we were able to assess the width of direction tuning, the cross-angle invariance of PMselectivity, and the difference in response strength between i) a single grating moving in the preferred direction, versus ii) the same grating moving in the preferred direction when it is presented as part of a plaid.

In our dataset, the tuning width of the PM-selective neurons was not significantly different from the tuning width of either unclassified or CM-selective cells. In fact, if anything, it was smaller: the median tuning bandwidth for PM-selective cells was $\sim 22^{\circ}$, compared with $\sim 30^{\circ}$ for CM-selective cells and $\sim 28^{\circ}$ for unclassified cells (data from 225 cells that were direction selective for the gratings and displayed responses also for the $120^{\circ}$ crossangle plaid; 11 PM-selective, $28 \mathrm{CM}$-selective, and 186 unclassified cells derived from six animals). PM-selective neurons in mouse V1 did show pronounced cross-component suppression: the responses of a cell to plaids containing a grating moving in its preferred direction were reduced compared to responses elicited by the grating presented alone. On average, the suppression was stronger for PM-selective versus CM-selective and unclassified cells [suppression index $(R$ (plaid) $/ R$ (grating)): PM-selective cells, $0.13(n=11)$; other direction-selective cells, $0.28(n=214)$; $p=0.0082$, Wilcoxon rank-sum test]. However, PM selectivity in mouse V1 is not cross-angle invariant, as PM-selective cell responses are generated for a narrower range of plaid cross-angles than would be typical for most units in monkey area MT. Once the cross-angle changes significantly, the responses become unclassified in the mouse (see Fig. 11).

These observations together suggest that a cascade model like the one described by Rust et al. (2006), will need to be significantly modified from its current form in order to apply in mouse V1. Direction-selective cells in retina and LGN have considerably broader tuning than direction-selective cells in the V1, including PM-selective cells (Chen et al., 2009; Marshel et al., 2011), suggesting a different mechanism may be operating. The sensitivity of the PM responses to the cross-angle of the plaid suggests that PM-selectivity may rather rely on the geometry of the receptive field of the cell and whether local contrasts ("blobs") exactly fit the on/off-subfields. This is akin to a process described by Tinsley et al. (2003) in a subset of unclassified marmoset V1 neurons that generated strong unidirectional responses to plaids. A change in cross-angle is thought to lead to the loss of size correspondence between local contrast blobs and the on/off-subfields, thereby engaging end-stopping mechanisms that suppress the response for certain directions (Tinsley et al., 2003). Overall, a more detailed study of receptive field properties and grating/plaid direction tuning functions is needed across various areas in the mouse visual system to pinpoint the precise mechanism of our observations.

\section{Bistable perception of two-dimensional drifting patterns in mice and the role of $\mathrm{V} 1$}

Additive full-field plaids belong to a class of stimuli that can induce bistable perception under certain stimulus conditions (Movshon et al., 1985; Stoner et al., 1990; Moreno-Bote et al., 2010). Large cross-angle between the components of the plaid, "transparency-promoting" intersection luminance values of the dark bars, and high grating velocity $(40 \%$ in our case) promotes the transparency percept (Movshon et al., 1985; Stoner et al., 1990; Moreno-Bote et al., 2010). At the same time, symmetry in component gratings' contrast, spatial frequency and velocity in our stimuli favor the coherent percept (Adelson and Movshon, 1982; Yo and Demer, 1992). At times, the observer perceives such plaids as two full-field component gratings sliding on top of each other, while, at other times, the perception spontaneously flips to a fused pattern drifting in a direction half-way between the directions of each component (Adelson and Movshon, 1982; Stoner et al., 1990; Moreno-Bote et al., 2010). It is an open question whether mice can perceive component versus pattern motion in plaid stimuli (Moreno-Bote et al., 2010). One reliable way to infer the perceptual state when a bistable visual motion stimulus is presented is to use the direction of the elicited optokinetic nystagmus (Enoksson, 1963; Fox et al., 1975; Logothetis and Schall, 1990; Wei and Sun, 1998; Watanabe, 1999; Naber et al., 2011). Coherent full-field moving visual stimuli, such as drifting gratings, dot fields, and coherently moving natural scenes induce reflexive OKN in mammals. These reflexive movements are primarily aimed at stabilization of the retinal input by compensating for the drift of visual environment. OKN eye movements consist of a slow pursuit in the direction of the stimulus followed by a quick saccade returning the eye to its initial position. OKN has been extensively validated as a reliable indicator of the dominant percept in experimental designs involving ambiguous stimuli, such as binocular rivalry (Fox et al., 1975; Logothetis and Schall, 1990; Wei and Sun, 1998; Watanabe, 1999; Naber et al., 2011). Under ambiguous visual conditions, the direction of pursuit during slow phases of OKN alternates in accordance with the direction of motion of the dominant percept.

To investigate the possibility that mice exhibit bistable perception, we checked whether optokinetic responses induced by drifting plaids exhibited bistable properties. We compared the direction of OKN elicited by simple gratings with the direction of OKN elicited by plaid stimuli in eight awake head-posted mice (Fig. 8). Stimuli were presented on three contiguous screens covering $\sim 270^{\circ}$ of the mouse visual field (Fig. $8 A, B$ ), and pupil movements were tracked via an infrared camera (Fig. $8 C$ ). Figure $8 D$ shows an example of OKN elicited by a horizontally oriented grating moving upward. As expected, in this case eye movements are vertically aligned $(h=0)$. Figure $8 E$ shows an example of OKN elicited by a vertically oriented grating moving horizontally in the temporonasal direction. As expected, in this case eye movements are exclusively horizontal $(v=0)$. Figure $8, F$ and $G$, show example OKN eye movements elicited by a $60^{\circ} \mathrm{CA}$ plaid whose pattern motion is horizontal in the temporonasal direction. Note that in Figure $8 G$ the $\mathrm{OKN}$ has a nonzero vertical component $(v)$ 
A

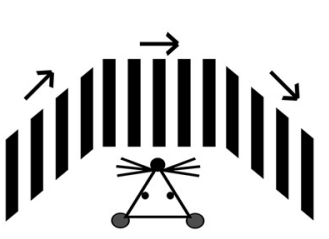

D

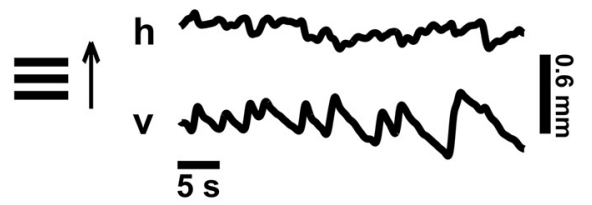

$\mathbf{F}$
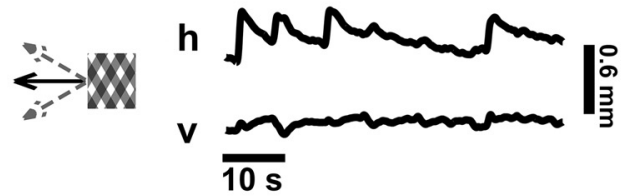

H
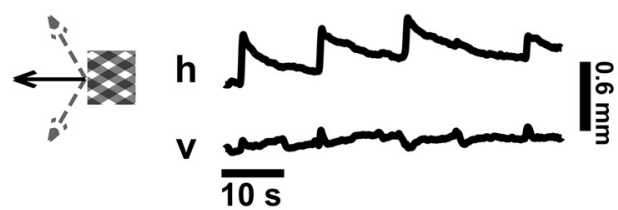

K

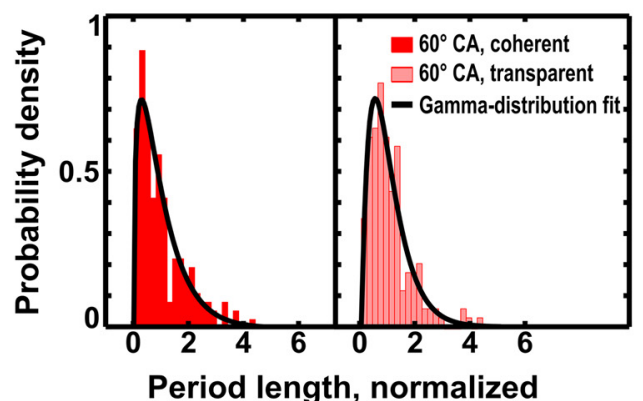



C

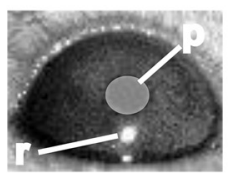

E
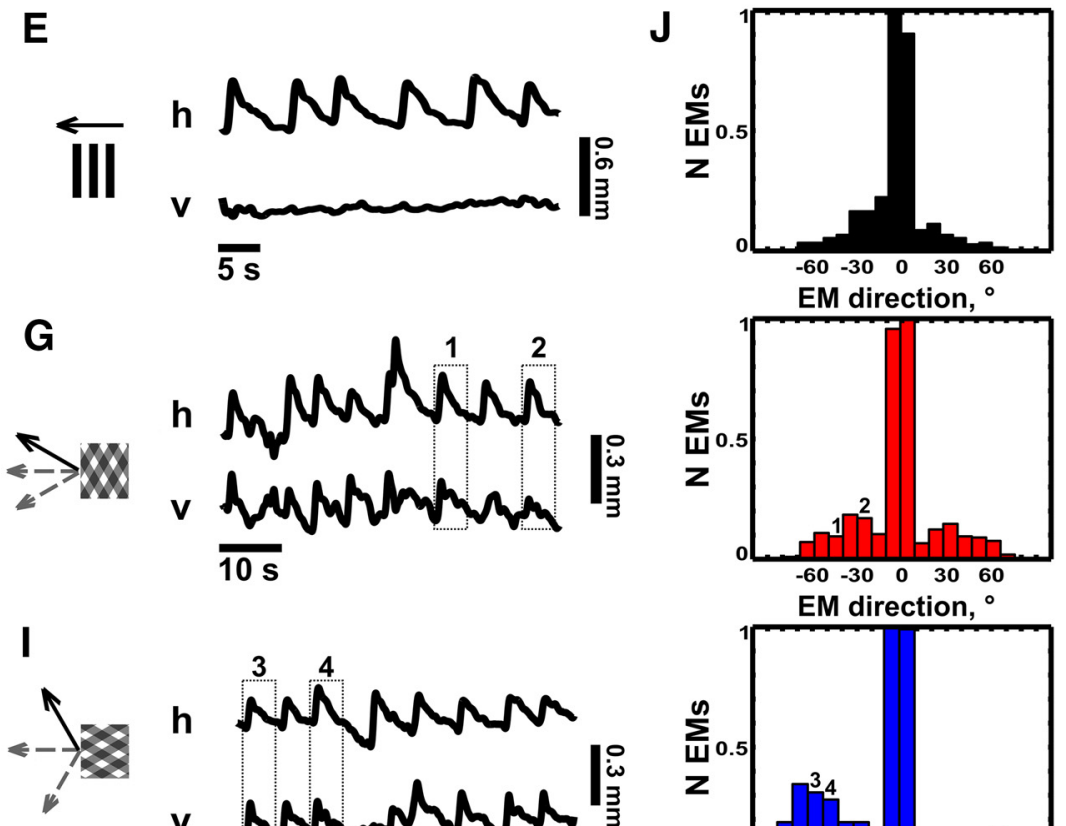

EM direction,

L

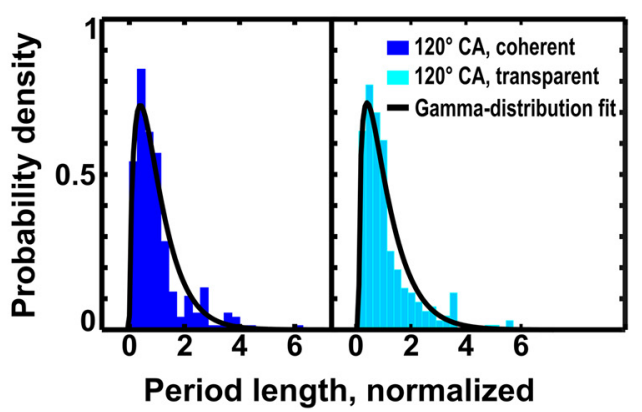

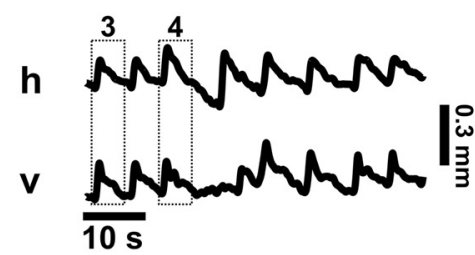

M

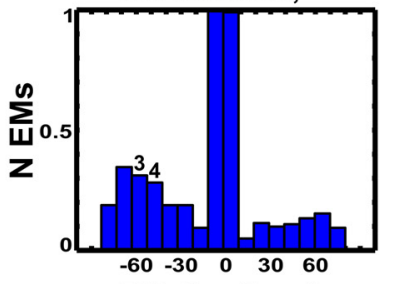

EM direction, ${ }^{\circ}$

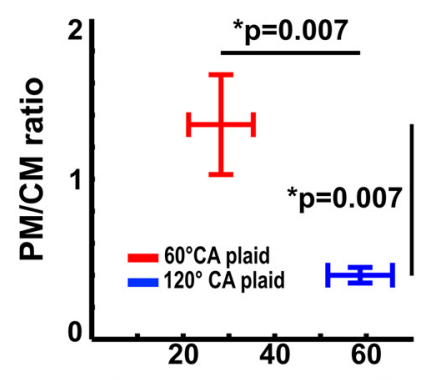

Component EMs, \%

Figure 8. Mice exhibit bistable $0 \mathrm{KN}$ responses. $A, B$, Experimental setup. We presented the stimulus on three screens positioned at equal distances around the mouse head to cover $\sim 270^{\circ}$ of the mouse visual field. We headposted the mouse to hold its head still and monitored EMs with an infrared camera (see Materials and Methods). Arrows, Direction of the drift of the stimulus. $A$, Setup for the recording of horizontal OKN. B, Setup for the recording of vertical OKN. C, Infrared image of a mouse eye. $r$, Reflection; $\boldsymbol{p}$, pupil. $\boldsymbol{D}$, Example of OKN elicited by a horizontally oriented grating drifting in the vertical direction (upward), as shown in B. v, Vertical eye position; $h$, horizontal eye position. As expected, OKN movements contain a clear vertical component, with no consistent horizontal deflections. $\boldsymbol{E}$, Example of $0 \mathrm{KN}$ elicited by a vertically oriented grating drifting in the horizontal direction, as shown in $A$. v, Vertical eye position; $h$, horizontal eye position. As expected, OKN movements contain solely a horizontal component, with no consistent vertical deflections. $F$, Example of OKN elicited by a $60^{\circ} \mathrm{CA} \mathrm{plaid} \mathrm{whose} \mathrm{global} \mathrm{pattern} \mathrm{is} \mathrm{drifting} \mathrm{in} \mathrm{the} \mathrm{horizontal} \mathrm{direction.}$ In this case, the eyes of the mouse follow the direction of motion of the global plaid pattern (horizontal), as is evident from the absence of a vertical OKN component. G, OKN elicited by the same $60^{\circ}$ CA plaid as in $\boldsymbol{F}$. In this case, the eyes of the mouse follow the direction of one of the component gratings of the plaid (the one moving toward $150^{\circ}$ ), as is evident from the combination of appropriate vertical and horizontal $0 \mathrm{KN}$ movements. $\boldsymbol{H}$, Example of $0 \mathrm{KN}$ elicited by a $120^{\circ} \mathrm{CA}$ plaid whose global pattern is drifting in the horizontal direction. As in $\boldsymbol{F}$, the mouse eye movements show purely horizontal OKN aligned with the direction of motion of the global plaid pattern. $I$, Example of component OKN, elicited by the same $120^{\circ} \mathrm{CA}$ plaid, as in $\boldsymbol{H}$. In this case, the eye of the mouse follows one of the component gratings of the plaid (the one moving toward $120^{\circ}$ ). J, Normalized histograms of the direction of nystagmoid EMs elicited by gratings and plaid stimuli, which are expressed as offsets from the horizontal OKN elicited by the vertically moving grating described in C. Black histogram (top, data from eight animals), EMs elicited by the vertically oriented horizontally moving grating; red histogram (middle, data from eight animals), EMs elicited by the $60^{\circ} \mathrm{CA}$ plaid, whose global pattern is moving in the horizontal direction; blue histogram (bottom, data from 8 eight animals), EMs elicited by the $120^{\circ} \mathrm{CA}$ plaid, whose global pattern is moving in the horizontal direction. Note that, as the cross-angle of the plaid increases, the histogram becomes trimodal, with one peak corresponding to the pattern motion, and the other two peaks to motion of the components of the plaid. When there is only a grating stimulus (top) the directions of $0 K N$ are clustered tightly around $0^{\circ}$ (mean $\pm S D=-3.2 \pm 19.5^{\circ}$; median $=0$ ). In contrast, for the $60^{\circ} \mathrm{CA}$ plaid a considerable fraction $(\sim 28 \%)$ of nystagmoid EMs lie beyond $1 \mathrm{SD}$ from the central peak (at $0^{\circ}$ ), corresponding to $0 \mathrm{KN}$ elicited by either one or the other of the plaid components. For the $120^{\circ} \mathrm{CA}$ plaid, component perception becomes more pronounced as $\sim 58 \%$ of nystagmoid EMs belong to the secondary modes ( $\pm 1 \mathrm{SD}$ from the central peak at $0^{\circ}$ ). These modes have peaks at $49 \pm 17.9^{\circ}$ and $-54.5 \pm 15.7^{\circ}$ (mean $\pm S D$ ), respectively, approximately corresponding to the directions of drift of the $120^{\circ} \mathrm{CA} \mathrm{components} \mathrm{of} \mathrm{the} \mathrm{plaid.} \boldsymbol{K}$, Distribution of durations of the periods of coherent (red histogram) versus transparent (pale-red histogram) motion perception induced by the $60^{\circ}$ plaid (eight mice; 175 transparent periods and 181 coherent periods). Before pooling, the dataset of each animal was normalized by its mean duration. Coherent, Red; (Figure legend continues.) 
that is consistent with tracking one of the component gratings of the plaid, while in Figure $8 \mathrm{~F}$ the $\mathrm{OKN}$ is purely horizontal $(v=0)$, consistent with tracking the global motion of the plaid pattern along the horizontal axis. Figure $8, H$ and $I$, show respective examples for $120^{\circ} \mathrm{CA}$ (Fig. $8 \mathrm{H}, \mathrm{I}$ ) plaids. Figure $8 \mathrm{~J}$ histograms the directions of all nystagmoid saccadic EMs elicited by each stimulus across all of the animals tested. Zero is taken along the nasotemporal direction, since OKN saccades are opposite to the direction of motion of the stimulus. As expected, moving gratings elicit a unimodal distribution (Fig. $8 J$, top, black) centered at zero. In contrast, the distributions elicited by the plaids (Fig. 8J, middle and bottom) are trimodal, with two additional emergent peaks centered approximately along the direction of motion of the plaid components. This strongly suggests that the perception of the mouse alternates between pattern and component motion, especially for the $120^{\circ} \mathrm{CA}$ plaid (Fig. $8 \mathrm{~J}$, bottom, blue).

We next studied the dynamics of alternation between tracking component gratings (transparent $\mathrm{OKN}$ ) and global pattern motion (coherent OKN), when viewing a drifting plaid pattern. The distribution of the durations of transparent and of coherent periods of OKN (see Materials and Methods) are shown in Figure $8 \mathrm{~K}$ for the $60^{\circ} \mathrm{CA}$ plaid (eight mice, $356 \mathrm{OKN}$ periods), and Figure $8 \mathrm{~L}$ for the $120^{\circ} \mathrm{CA}$ plaid (eight mice, $522 \mathrm{OKN}$ periods). To build the distributions of durations we pooled coherent and transparent OKN data separately from eight animals. The dataset for each animal was normalized by the mean of the dataset before pooling (Rubin and Hupé, 2004). The aggregate distributions were well fit by gamma-distribution functions (Rubin and Hupé, 2004). For the $60^{\circ} \mathrm{CA}$ plaid, the median length of the coherent OKN period was $22.7 \mathrm{~s}$, and the median length of the transparent OKN period was $14.4 \mathrm{~s}$. For the $120^{\circ} \mathrm{CA}$ plaid, the median length of the coherent OKN period was $12.5 \mathrm{~s}$, and the median length of the transparent OKN period was $13.5 \mathrm{~s}$. As expected, these results suggest that narrow plaids, such as $60^{\circ} \mathrm{CA}$, bias the $\mathrm{OKN}$ in favor of tracking the global direction of pattern motion (coherent $\mathrm{OKN})$. Plaids with larger CA $\left(120^{\circ}\right)$ are more likely to elicit component motion perception as manifested by a relative increase in the mean transparent OKN period compared with the mean coherent $\mathrm{OKN}$ period. In agreement with this, $28 \pm 6.5 \%$ (mean \pm SEM) of OKN eye movements followed the drift of component gratings for the $60^{\circ} \mathrm{CA}$ plaid, compared with $58.4 \pm 6.7 \%$ for the $120^{\circ} \mathrm{CA}$ plaid (Fig. $8 M$, horizontal axis; $n=8, p=0.007$, Wilcoxon rank-sum test). These results follow the general trend observed in prolonged viewing bistability experiments, where subjects report perceptual switches while viewing drifting plaids (for example, see Moreno-Bote et al., 2010). In particular, narrow-angle plaid $\left(60^{\circ} \mathrm{CA}\right)$ biases perception in favor of the

\section{$\leftarrow$}

(Figure legend continued.) transparent, pale red. The distributions were fit with gamma distribution (coherent, $p=0.017$; transparent, $p=0.031 ; \chi^{2}$ test). L, Distribution of durations of the periods of coherent (blue histogram) vs transparent (cyan histogram) motion perception induced by the $120^{\circ}$ plaid (eight mice; 264 transparent periods and 258 coherent periods). Before pooling, the dataset of each animal was normalized by its mean duration. Coherent, Blue; transparent, cyan. The distributions were fit with gamma distribution (coherent, $p=$ 0.000018 ; transparent, $p=0.00005 ; \chi^{2}$ test). $\boldsymbol{M}$, The increase in angle between the plaid components correlates with an increase in the relative fraction of transparent $0 \mathrm{KN}$, and with a shift in the ratio between PM-selective and CM-selective neuronal responses in favor of $\mathrm{CM}$ selectivity. Error bars represent the SEM. Red, $60^{\circ} \mathrm{CA}$ plaid data; blue, $120^{\circ} \mathrm{CA}$ plaid data. Two-photon data, $n=6$ animals; EM analysis, $n=8$ animals. Significance testing across animals: Wilcoxon rank-sum test: $p=0.007$ for PM/CM ratio shift and component EM fraction change. coherent motion state, resulting in larger mean duration for the coherent-motion percept (in human subjects: coherent percept duration, $\sim 30 \mathrm{~s}$; transparent percept duration, $\sim 3 \mathrm{~s}$; MorenoBote et al., 2010). At the same time, large-angle plaids between $110^{\circ}$ and $130^{\circ} \mathrm{CA}$ resulted in a nearly equidominant state, with the mean duration of the coherent percept being nearly equal to the mean duration of the transparent percept $(\sim 5-7 \mathrm{~s}$ for human observers; Hupé and Rubin, 2003; Moreno-Bote et al., 2010). Although in our OKN data the median durations of stable perceptual epochs were longer (12-23 s), our general findings correspond qualitatively well to results obtained in human observers under prolonged viewing conditions. Specifically, (1) narrowangle plaids result in prolonged coherent OKN periods and shorter transparent OKN periods, while (2) large-angle plaids result in nearly equal durations of transparent and coherent $\mathrm{OKN}$ periods.

It is possible that the relative strength of the population activity of pattern-motion-selective responses versus component-motion-selective responses of V1 cells may contribute to the bias in both the direction of OKN and the underlying direction of motion of the visual percept. Interplay between orientation-based, component-selective V1 input and retinal direction-selective input to $\mathrm{OKN}$-generating nuclei in the brainstem was proposed to affect the direction of plaid-induced OKN in cats (Smith and Harris, 1991). In birds the OKN-generating brainstem nuclei were shown to contain mainly pattern-motion-selective units, receiving dense projections from retinal direction-selective units, and only very scarce projections from component-motion-selective neurons of visual wulst (avian V1 analog; Crowder and Wylie, 2002). Mouse V1 population responses to $120^{\circ} \mathrm{CA}$ plaids showed significant bias toward $\mathrm{CM}$-selective versus $\mathrm{PM}$-selective responses: the $\mathrm{PM} / \mathrm{CM}$ cell ratio was $1.3 \pm 0.32$ for $60^{\circ} \mathrm{CA}$ plaids compared with $0.32 \pm 0.1$ for $120^{\circ}$ CA plaids (Fig. $8 M$; $n=6$, $p=0.007$, Wilcoxon rank-sum test). This suggests that the relative proportion of $\mathrm{PM}$-selective versus $\mathrm{CM}$-selective responses in mouse $\mathrm{V} 1$ may play a role in biasing OKN direction, and therefore perception, toward pattern or component motion. However, a more basic question needs to be asked first. In rodents, OKN is known to depend mainly on subcortical structures with no critical contribution of visual cortex (Harvey et al., 1997), and it is far from clear whether the observed OKN transitions are influenced, or not, by V1 input.

To collect further evidence regarding whether V1 input contributes to bistable OKN in the mouse, we performed lesion studies in seven animals. The dominant subcortical pathway for OKN generation relies on the activity of the nucleus of optic tract (NOT), driven by direct input from retinal ganglion cells (Ballas et al., 1981). The cortical pathway consists of visual cortical inputs to the NOT cells, coming from both area V1 and extrastriate visual cortex (Smith and Harris, 1991; Distler and Hoffmann, 2001). Specifically, in rodents, direction-selective cells of the NOT-dorsal terminal nucleus (DTN) complex, which is involved in the generation of optokinetic eye movements, receive direct cortical input from areas V1 and V2 (Schmidt et al., 1993). It is conceivable that this corticofugal input to NOT influences the direction of elicited $\mathrm{OKN}$ and the direction of motion of the dominant percept. In rodents with laterally located eyes, known direct visual cortical inputs to NOT are predominantly ipsilateral (Schmidt et al., 1993). Therefore, unilateral V1 lesions are expected to mostly affect OKN elicited by stimuli presented in the contralateral visual field, leaving ipsilateral stimulus presentation as an in- 
A

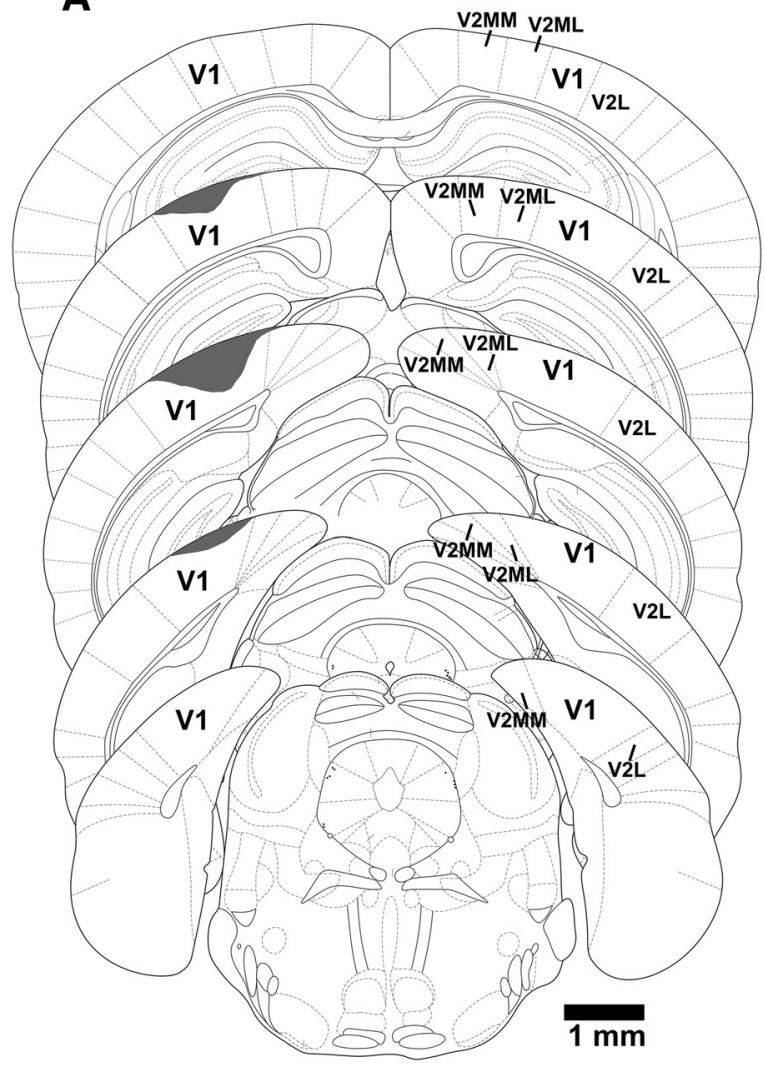

B

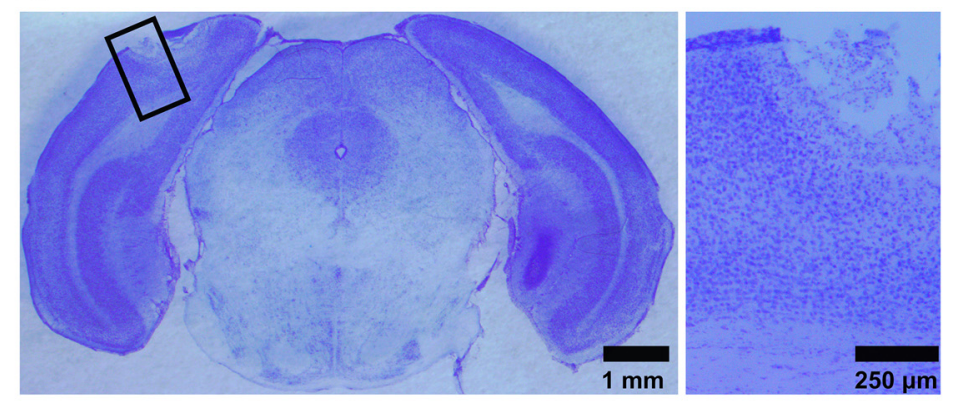

C

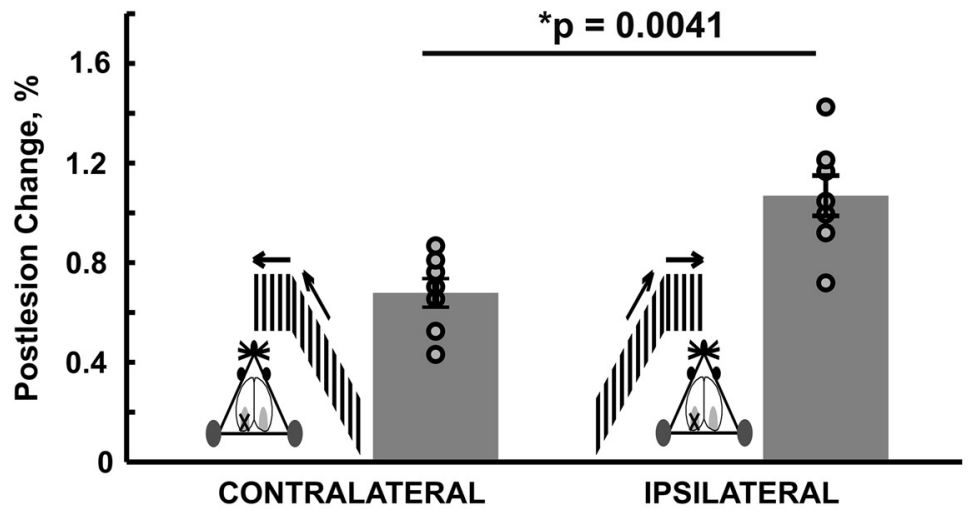

Figure 9. V1 lesions alter bistable optokinetic responses. $A$, Lesion location in the V1 (shaded areas, one mouse). The slice schematics are adapted from the atlas of the mouse brain by Paxinos and Franklin (2001), and lesion position is derived from Nissl-stained brain sections. Lesioned areas are shaded in gray. The $60 \mu \mathrm{m}$ slices are shown at $\sim 600 \mu \mathrm{m}$ intervals from each other. Across mice, the maximal lateral width of the lesion in V1 was between 0.8 and $1.8 \mathrm{~mm}$. Sagittally, the lesions extended between 2.7 and $4.5 \mathrm{~mm}$ caudal to the bregma. $\boldsymbol{B}$, Left, Nissl-stained coronal section of the mouse brain ( $\sim 4 \mathrm{~mm}$ caudal to the bregma), showing the lesion in V1. Box, Lesioned area, shown on the right; right, lesion position in the cortical thickness. $C$, The effect of the unilateral V1 lesion on the $0 \mathrm{KN}$ responses recorded from contralateral versus ipsilateral eyes (to the lesion). The percentage of component-aligned eye movements recorded from each eye before and $3-25 \mathrm{~d}$ after the lesions were compared. Insets show the stimulus arrangement for monocular stimulation (see also Materials and Methods). Crosses mark the V1 containing the lesion. Left column, Contralateral eye stimulation and recording; right column, ipsilateral eye stimulation and recording. Dots stand for individual data points. After the lesion, when the contralateral eye was driving the OKN, the percentage of component-aligned eye movements decreased consistently in all examined animals. If ipsilateral eye stimulation was driving the 0KN, the percentage of component-aligned eye movements mostly showed small changes, and the direction of those changes was inconsistent across the animals. Bars, Relative change of the fraction of component-aligned eye movements for ipsilaterally and contralaterally driven OKN after the lesion, with data from across seven animals (mean \pm SEM); ipsilateral $0 \mathrm{KN}, 1.07 \pm 0.09$; contralateral $0 \mathrm{KN}, 0.68 \pm 0.06$. While there was a significant overall decrease in the fraction of component-aligned movements in contralaterally driven OKN, the ipsilaterally driven OKN properties on average did not change across seven animals (Wilcoxon rank-sum test, $p=0.0041, n=7$ ).

ternal control. We induced unilateral V1 lesions centered in the stereotaxic center of V1 by laser photocoagulation (see Materials and Methods; Fig. 9A,B), and recorded OKN responses prelesion and following recovery. Visual stimuli always drifted in the temporonasal direction, which is the direction that generates strong nystagmoid responses in the mouse (Cahill and Nathans, 2008). Both contralaterally and ipsilaterally driven $\mathrm{OKN}$ responses to $120^{\circ} \mathrm{CA}$ plaids were recorded and compared.

We found that unilateral V1 lesions changed the distribution of component versus pattern OKN responses to contralaterally presented plaid stimuli. Specifically, for contralaterally (but not for ipsilaterally) presented $120^{\circ} \mathrm{CA}$ plaids, the fraction of transparent OKN dropped by $\sim 33 \%$ (Fig. $9 C$; Wilcoxon rank-sum test, $n=7, p=0.0041)$. In contrast, optokinetic responses to ipsilaterally presented $120^{\circ}$ CA plaids (internal control) remained unchanged (Fig. 9C). This strongly suggests that area V1, either directly by input to OKN neurons (Schmidt et al., 1993) or indirectly by influencing other visual areas or subcortical structures projecting to NOT (Schmidt et al., 1993; Distler and Hoffmann, 2001; Hoffmann et al., 2002), makes a contribution to determining the direction of OKN movements induced by bistable stimuli. Note that this result is not trivial since, in rodents, $\mathrm{OKN}$ induced by nonambiguous stimuli (drifting gratings) remains essentially unaffected, even by complete bilateral removal of visual cortex (Harvey et al., 1997). Interestingly, the percentage of component-aligned transparent OKN is reduced after V1 lesions, which is in line with the fact that there is a preponderance of component-motion-selective responses for the $120^{\circ}$ crossangle plaid in the mouse V1. This may be potentially explained if one entertains the hypothesis that input from area V1 component-selective units to NOT is now reduced because of the lesion. However, this interpretation needs to be tempered by the fact that (1) extrastriate areas receiving V1 input also project to NOT (Schmidt et al., 1993; Distler and Hoffmann, 2001; Hoffmann et al., 2002) and (2) it is not known at present how component-motion-selective versus pattern-motion-selective units in these areas behave following V1 lesions. In any event, it appears that the phenomenon of OKN bistability in the mouse does not depend exclusively on the response of subcortical nuclei, but receives an important contribution from cortical (striate and/or extrastriate) feedback. 


\section{Discussion}

Complex motion properties of neuronal responses in mouse $\mathrm{V} 1$ differ from cat and primate $\mathrm{V} 1$

We show that layer $2 / 3$ of mouse V1 contains, on average, $\sim 10 \%$ neurons that are capable of pattern-motion-selective responses (pooled $60^{\circ}$ and $120^{\circ}$ plaid data) compared with $\sim 1.3 \%$, on average, in cat and primate V1 (Fig. $6 B$; Table 1). Moreover, only $\sim 17 \%$ of direction-selective units in mouse V1 were selective for component motion compared with $66-100 \%$ for cats or primates (depending on the study; Table 1). Even if one excludes $60^{\circ}$ CA plaid data, for which $\mathrm{CM}$ versus $\mathrm{PM}$ classification is arguably less reliable, the same conclusion holds. For $120^{\circ} \mathrm{CA}$ plaids, mouse V1 has $\sim 6 \% \mathrm{PM}-$ selective and $\sim 20 \%$ CM-selective neurons, compared with $\sim 1.3 \%$ PM-selective and $\sim 84 \% \mathrm{CM}$-selective units in cat and primate $\mathrm{V} 1$, over a range of comparable plaid cross-angles (Fig. 6A,B). Even more revealing is the shape of the distribution of mouse V1 neuron selectivity in the $R_{p}$ versus $R_{c}$ or the $z$-score space, which differs markedly from that of cat or primate V1 (Figs. 4, 5). This distribution is unimodal, suggesting that PM and CM classification of mouse V1 neurons is not discrete but a continuous process. These observations also carry over to layers $4-6$ of mouse V1, which have $\sim 7.8 \%$ of PM-selective and $\sim 8.2 \%$ of CM-selective responses and unimodal distributions of PM/CM selectivity (Fig. 7B).

Two recent studies (Juavinett and Callaway, 2015; Muir et al., 2015) similarly classified mouse V1 neurons using partial correlation analysis (Movshon and Newsome, 1996; Smith et al., 2005), or a modified partial correlation analysis taking into account single-trial variability of visual responses (Muir et al., 2015). Study 1 (Juavinett and Callaway, 2015) found 70\% unclassified and 30\% component-motion-selective cells in mouse $\mathrm{V} 1$, but no cells with clear pattern-motion-selective responses. Juavinett and Callaway (2015) argue that, similar to primates, complex visual motion processing takes place mainly in higher areas, while mouse V1 mainly processes component-motion. Study 2 (Muir et al., 2015) found $\sim 3 \%$ of pattern-motionselective cells and $\sim 31 \%$ of component-motion-selective cells in mouse V1. By comparison, we find $\sim 10 \%$ of pattern-motionselective and $\sim 17 \%$ component-motion-selective neurons (pooled $120^{\circ}$ cross-angle plaid and $60^{\circ}$ cross-angle plaid data).

Notwithstanding the lower fraction of PM-selective units, the distributions of $R$ values or $z$-scores in these two studies are similar to those of our study and do not conform to the situation typically found in monkey and cat V1 (Figs. 4C, 5C), where 66$100 \%$ of direction-selective cells are component-motion selective, and, at best, only a small minority of cells remains unclassified. In all three studies, the large majority of mouse V1 cells could not be classified, despite having reliable responses and sharp direction tuning. Accordingly, compared with the $\sim 84 \%$ component-selective units reported in primate V1 (Table 1), in mouse V1 Juavinett and Callaway (2015) report 30\%, Muir et al. (2015) report $\sim 31 \%$, and we, at best, report $\sim 20 \%$ (for the $120^{\circ}$ CA plaid).

The main difference between the studies is the higher fraction of pattern-motion-selective cells we find ( $10 \%$ vs $\sim 0 \%$ in the study by Juavinett and Callaway, 2015, and 3\% in the study by Muir et al., 2015). The reason for this difference may be, in part, methodological (i.e., differences in plaid cross-angle, grating spatial frequency, or stimulus drift velocity). However, this is unlikely to be the whole story, as our grating parameters $(0.05$ cycles $/{ }^{\circ}$ and $2 \mathrm{~Hz}$ ) were close, though not identical, to those of Juavinett and Callaway (2015; 0.025-0.04 cycles $/{ }^{\circ}$ and $1-2 \mathrm{~Hz}$ ) and Muir et al. (2015; 0.04 cycles/ ${ }^{\circ}$ and $1.5 \mathrm{~Hz}$ ). Furthermore,
Juavinett and Callaway (2015) used plaids with a cross-angle of $120^{\circ}$, similar to us, while Muir et al. (2015) relied on plaids of $90^{\circ}$ cross-angle, which would be expected, if anything, to increase the fraction of pattern-motion-selective units (Juavinett and Callaway, 2015; Muir et al., 2015). Selectivity for pattern-motion in mouse V1 may also be modulated by other receptive field properties, as argued by Tinsley et al. (2003), who noted that differences in pattern-motion selectivity may be attributed to different V1 receptive field aspect ratios in the marmoset. Another factor that may have contributed to the difference between studies is the different degree of coverage of the visual field by the stimulus. We and Muir et al. (2015) used stimuli covering $\sim 80^{\circ} \times 80^{\circ}$, whereas the stimuli of Juavinett and Callaway $(2015)$ were larger $\left(\sim 112^{\circ}\right.$ $\left.\times 112^{\circ}\right)$. Thus, it may be that we and Muir et al. (2015) stimulated a smaller portion of the surround, leading to stronger cellular responses that may favor pattern selectivity.

In summary, although further work is needed to delineate the mechanisms of complex motion processing in both mouse and primate $\mathrm{V} 1$, the weight of the evidence suggests that mouse V1 cannot be considered a complete analog of cat or primate $\mathrm{V} 1$ in terms of complex motion processing. Rather, it seems to have some properties usually associated with extrastriate areas in higher mammals, namely, the presence of PM-selective responses and a markedly lower percentage of CM-selective cells compared with cat and primate V1.

\section{Unclassified cells may contribute to motion processing in the mouse}

Interestingly, $6-21 \%$ of cells that have sharp direction tuning but remain unclassified do show a degree of preference for pattern motion (Fig. 10). Such cells may well contribute to motion integration when taken at the population level (Fig. 10C,D). As expected, in this group of cells, the fraction of responses favoring pattern motion decreases as the plaid cross-angle increases. Therefore, in this respect they behave similarly to the population of cells classified as pattern-motion or component-motion selective (Figs. $8 M, 10 D)$.

Another striking difference between mouse and cat/primate $\mathrm{V} 1$ is that mouse V1 has a relative abundance of cells that generate tuned responses for plaid pattern motion, but are not responsive to moving gratings (Juavinett and Callaway, 2015, 37\%; our study, $\sim 20 \%$ of all pyramidal cells, and $32 \%$ of visually responsive cells). These "plaid-exclusive" cells remain invisible to the partial correlation classification procedure because they do not generate responses for the gratings. However, since they are tuned to the direction of motion of the plaid, they could support alternative schemes of motion encoding in mouse V1. To our knowledge, such cells have not been reported in the V1 of primates (A. Movshon, personal communication) but are found in primate MT (Solomon et al., 2011).

\section{Pattern-motion selectivity in mouse V1}

In mouse $\mathrm{V} 1$, we identified a population of neurons $(6-15 \%)$ that were PM-selective and another $(6-21 \%)$ that were unclassified but PM-sensitive, depending on plaid angle. The ability of a cell to show PM-selective or PM-sensitive responses strongly depends on the cross-angle of the plaid (Figs. 10, 11). In primates, PM-selectivity in higher visual areas is thought to arise by cells pooling inputs from component motion-selective V1 neurons (Movshon and Newsome, 1996). In mouse V1, it is possible that PM-selectivity arises locally by integrating the responses of neighboring CM-selective units and direction-selective unclassified cells. Alternatively, the integration of direction-selective feedfor- 
A

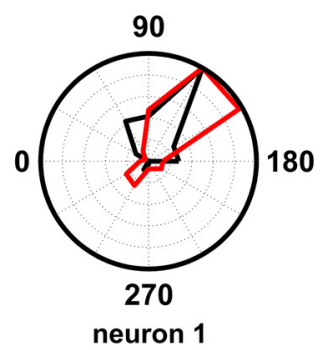

C

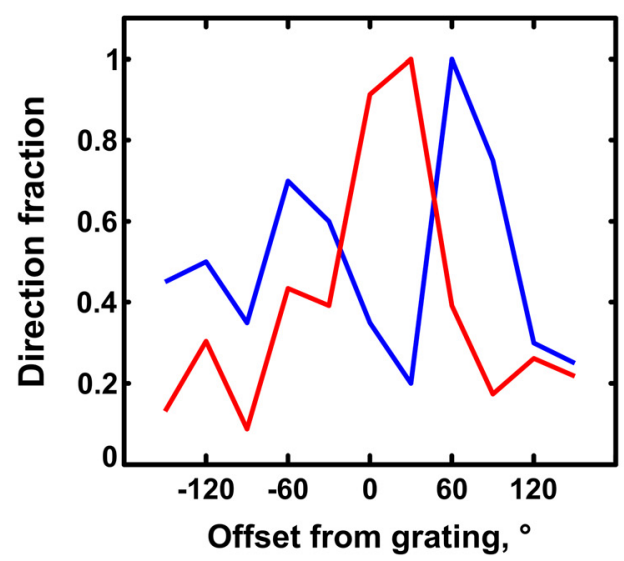

B
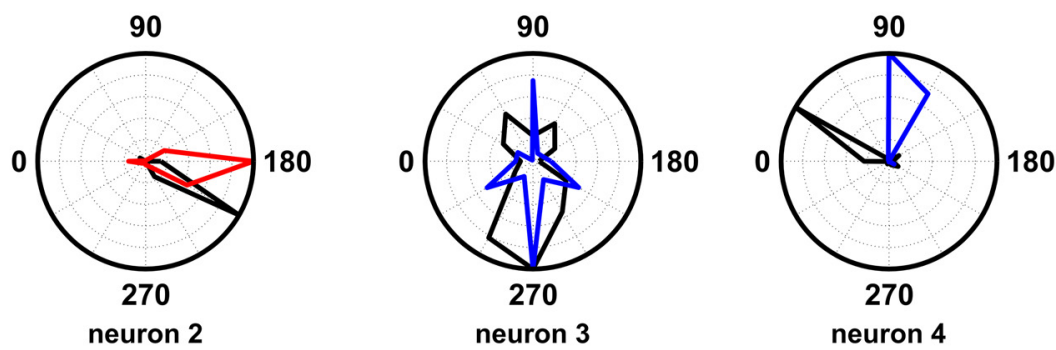

D

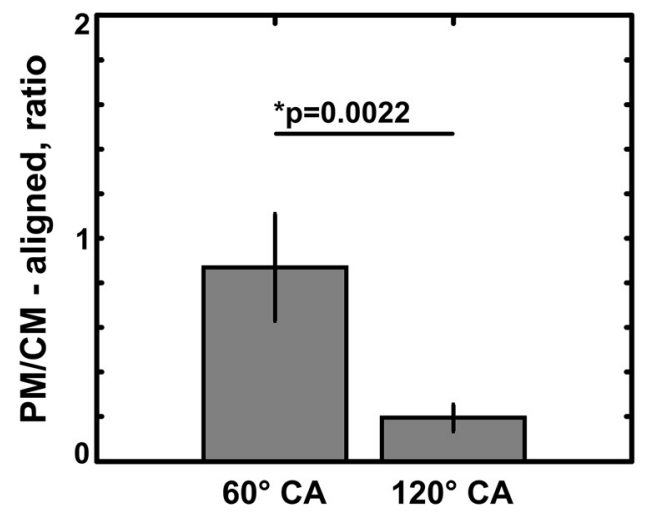

Figure 10. Unclassified direction-selective cells may contribute to population coding for pattern and component motion. $\boldsymbol{A}, \boldsymbol{B}$, Examples of plaid tuning found among direction-selective unclassified cells. $\boldsymbol{A}$, Responses elicited with the $60^{\circ} \mathrm{CA}$ plaid (red) vs a drifting grating (black). $\boldsymbol{B}$, Responses elicited with the $120^{\circ} \mathrm{CA}$ plaid (blue) vs a drifting grating (black). When tested with plaid stimuli, $\sim 60 \%$ of unclassified cells show unidirectional tuning or bidirectional tuning with opposite peaks. The peak of the tuning curves of the cells for plaids have variable offsets in relation to the peak of their tuning curves for gratings. This is the main reason that these cells failed to classify as clear component-motion or pattern-motion cells. We define neuron 2 and neuron 4 as being component-motion sensitive, since the peaks of the respective plaid tuning curves shift from the grating tuning curve peaks by half of the cross-angle of the plaid. Neuron 1 and neuron 3 are pattern-motion sensitive, since the dominant peaks for the plaid tuning curve are exactly aligned. C, Distribution of tuning curve peak offsets for the population of unimodal unclassified cells for $60^{\circ}$ plaids (red, $n=116$ ) and $120^{\circ}$ plaids (blue, $n=96$ ). The tuning curve peaks elicited by the drifting grating are set at $0^{\circ}$ offset. While a considerable fraction of $60^{\circ}$ plaid tuning curves share their peak with the grating tuning curve ( $\sim 21 \%$ ), most tuning curves for $120^{\circ}$ plaids deviate significantly: only $6 \%$ are exactly aligned with the peak of the tuning curve of the grating, while a significant proportion ( $\sim 31 \%$ ) are offset by $60^{\circ}$. D. The ratio of pattern-motion-sensitive (PM-aligned) unclassified responses to component-motion-sensitive (CM-aligned) unclassified responses is significantly shifted in favor of component-motion-sensitive unclassified responses for the large-angle plaids ( $120^{\circ}$ cross-angle; $p=0.0022$, Wilcoxon rank-sum test). $60^{\circ}, 0.87 \pm 0.24$ ( $n=6$ animals); $120^{\circ}, 0.195 \pm 0.07$ ( $n=6$ animals). Error bars: mean \pm SEM.

ward subcortical inputs from the LGN or superior colliculus pathways may contribute to PM-selective responses in mouse V1. In the mouse, both retina (Kay et al., 2011) and LGN (Piscopo et al., 2013) have a substantial percentage $(\sim 11 \%)$ of direction-ofmotion-selective cells. Cells with plaid-exclusive responses or pattern-motion-selective responses could be the cortical recipients of the pathway described in the mouse by Cruz-Martin et al. (2014), which originates in direction-of-motion-selective retinal ganglion cells and projects to superficial layers of V1, bypassing layer 4.

PM-selective properties may also arise as a function of feedback from higher motion-selective areas (Movshon and Newsome, 1996; Guo et al., 2004), although this is less likely since we performed our measurements under anesthesia (Guo et al., 2004).

Finally, PM-selectivity may arise directly as an integration property of the receptive field itself, rather than by pooling the responses of more "fundamental" orientation-responsive units. Such a mechanism was suggested by Tinsley et al. (2003), who reports that pattern motion responses in marmoset V1 strongly depend on the ability of the cell to respond to local contrasts of varying size and shape that are present in the globally moving plaid. Layer $2 / 3$ of mouse V1 has two features that make this explanation especially appealing. First, the selectivity of individ- ual neurons for pattern versus component motion in mouse V1 varies strongly with the cross-angle of the plaid (Fig. 11). Specifically, in the population of PM-selective and CM-selective cells, $\sim 66 \%$ of neurons generate selective responses solely for the plaid of a specific cross-angle, while plaids of other cross-angles elicit unclassified responses. Second, a large fraction ( $32 \%)$ of visually responsive cells in mouse $\mathrm{V} 1$ generate directionally tuned responses to moving plaid patterns, but not to drifting gratings. These two phenomena may be explained if it turns out that direction-of-motion responses for plaids in mouse V1 depend strongly on the geometry of plaid intersections.

Alternatively, cells with plaid-exclusive responses or patternmotion-selective responses may inherit their direction selectivity from retinal ganglion cells with center-surround receptive fields favoring moving elements with short aspect ratios (e.g., plaid intersection contrasts), rather than from cortical cells with orientation-selective receptive fields (Cruz-Martin et al., 2014).

The fact that different proportions of PM-selective versus CM-selective cells are found in area V1, depending on the plaid cross-angle, could influence visual perception in the mouse. The causality of this proposition is beyond our ability to prove here, but the optokinetic analysis we performed suggests that it is at least possible. In what follows, we discuss the contribution of area V1 to plaid-elicited optokinetic responses in the mouse. 

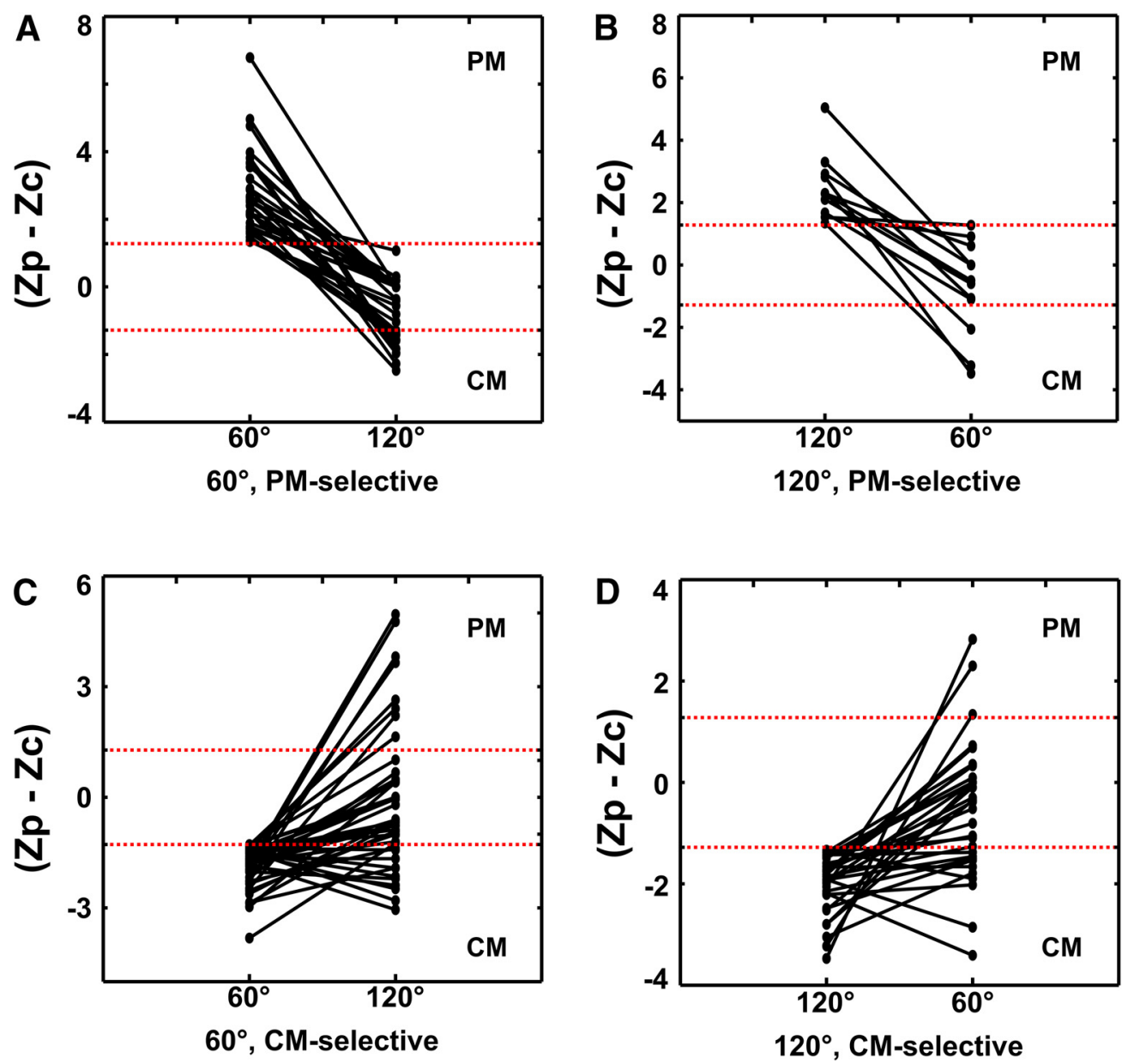

Figure 11. Pattern-motion and component-motion selectivity in mouse V1 depends on the cross-angle of the plaid. Each graph plots the shift in the difference between pattern motion and component motion $z$-scores (i.e., $Z_{p}-Z_{c}$ ) for the $60^{\circ} \mathrm{CA}$ (narrow) plaid and the $120^{\circ} \mathrm{CA}$ (wide) plaid. If the cell lost tuning or became unresponsive as a result of change in the cross-angle of the plaid, $\left(Z_{p}-Z_{c}\right)$ was set to 0 . Areas of the plot that contain PM-selective $\left(Z_{p}-Z_{c}>1.28\right)$ or $C M$-selective responses $\left(Z_{p}-Z_{c}<-1.28\right)$ are marked with PM and $C M$, respectively. Space between dotted red borders contains unclassified responses. $A$, Neurons that are pattern-motion selective for the $60^{\circ} \mathrm{CA}$ plaid; $63 \%$ of neurons that produced pattern-motion-selective responses for the $60^{\circ}$ plaid (left column) had unclassified responses when tested with the $120^{\circ} \mathrm{CA}$ plaid. A minority (37\%) of the neurons became CM-selective when tested with $120^{\circ} \mathrm{CA}$ plaid. $\boldsymbol{B}$, Neurons that are PM-selective for the $120^{\circ} \mathrm{CA} \mathrm{plaid} ; 75 \%$ of neurons that produced pattern-motion-selective responses for the $120^{\circ}$ plaid (left column) became unclassified when tested with the $60^{\circ} \mathrm{CA}$ plaid. Another $25 \%$ of these neurons showed $\mathrm{CM}$-selective responses for the $60^{\circ} \mathrm{CA}$ plaid. C, Neurons that are component-motion selective for the $60^{\circ} \mathrm{CA}$ plaid; $55 \%$ of neurons that produced component-motion-selective responses for the $60^{\circ}$ plaid (left column) became unclassified when tested with the $120^{\circ} \mathrm{CA}$ plaid. Another $26 \%$ of these neurons stayed CM-selective, while $19 \%$ showed PM-selective responses for the $120^{\circ} \mathrm{CA}$ plaid. $\boldsymbol{D}$, Neurons that are component-motion selective for the $120^{\circ} \mathrm{CA}$ plaid; $55 \%$ of neurons that produced component-motion-selective responses for the $120^{\circ}$ plaid (left column) became unclassified when tested with the $60^{\circ} \mathrm{CA}$ plaid. Another $35 \%$ of these neurons stayed CM-selective, while $10 \%$ showed PM-selective responses for the $60^{\circ} \mathrm{CA}$ plaid.

\section{Contribution of area V1 to bistable optokinetic nystagmus in the mouse}

Our optokinetic nystagmus experiments clearly demonstrate that mice are capable of bistable optokinetic responses when presented with moving plaid stimuli (Fig. 8). Since the direction of optokinetic nystagmus correlates well with the perceived direction of motion of the nystagmus-inducing stimulus (Fox et al., 1975; Logothetis and Schall, 1990; Wei and Sun, 1998; Naber et al., 2011), this result argues strongly in favor of the richness of the mouse visual system and its appropriateness as a model of visual perception.

To test whether area V1 plays a role in the bistability of the $\mathrm{OKN}$, we investigated the effect of $\mathrm{V} 1$ lesions on $\mathrm{OKN}$ responses elicited by $120^{\circ} \mathrm{CA}$ plaids. In rodents, direction-selective cells of NOT-DTN complex that generate OKN eye movements receive direct cortical inputs from V1 neurons of the ipsilateral V1 (Schmidt et al., 1993). We show that, following unilateral V1 lesion, the fraction of eye movements along the direction of the plaid components fell to $0.68 \pm 0.06$ compared with before the lesion, an $\sim 33 \%$ reduction. At the same time, OKN driven by temporonasal stimulation of the ipsilateral visual field (intact V1, internal control) remained, on average, unchanged (Fig. 9C). These data show that the bistable OKN induced by complex (plaid) motion stimuli does not depend exclusively on subcortical responses but receives a significant contribution from cortical inputs. Note that this result is not trivial since, in rodents, $\mathrm{OKN}$ induced by nonambiguous stimuli (drifting gratings) remains essentially unaffected, even by complete bilateral removal of visual cortex (Harvey et al., 1997). We stress that this contribution may arise directly from area V1, through its projection to NOT, or indirectly, through the projections to NOT from extrastriate areas that depend on V1 input.

This perceptual bistability shifts in favor of perceiving component motion for plaids with higher cross-angle $\left(120^{\circ}\right.$; Fig. $\left.8 \mathrm{M}\right)$, which is in agreement with prior psychophysical studies in other mammals (Kim and Wilson, 1993; Hupé and Rubin, 2003; Moreno-Bote et al., 2010). Interestingly, the ratio of PM-selective versus $\mathrm{CM}$-selective neuronal responses seen in mouse V1 also drops with increasing plaid cross-angles (Fig. 8M). A similar 
trend is observed in unclassified V1 neurons that display patternmotion or component-motion sensitivity: their population response also shifts in favor of component motion for plaids of larger cross-angles (Fig. 10D). This suggests that V1 population input to NOT (directly or indirectly via extrastriate areas) is more biased toward component motion for larger cross-angles. It may, therefore, contribute to biasing the direction of the OKN to reflect increased component motion perception for those angles.

\section{Conclusion}

Our findings show that the classification of V1 neurons as pattern-motion selective or component-motion selective differs between mouse and primates. Specifically, mouse V1 contains a larger (6-15\%, depending on the cross-angle and the layer) fraction of PM-selective cells, as well as much fewer $(\sim 8-20 \%) \mathrm{CM}$ selective cells compared with primate V1 (PM-selective units, $<1.3 \%$; CM-selective units, $\sim 84 \%$ ). In addition, $52 \%$ of unclassified direction-selective cells in mouse V1 generate responses that still contain information about pattern or component motion, which may support pattern-motion or component-motion sensitivity at the population level (Fig. 10). Finally, a significant proportion $(20 \%)$ of pyramidal cells in mouse V1 generate direction-selective responses to plaid but not to grating motion, and thus are capable of processing complex plaid motion directly. Further, we provide strong evidence that the visual system of the mouse exhibits bistable motion perception of plaid stimuli, which, at least in part, depends on area V1 input. Together, the above results suggest that mouse area $\mathrm{V} 1$, in addition to processing locally oriented motion components can also contribute directly to complex motion processing of plaid stimuli and to the bistable motion perception induced by these stimuli.

\section{References}

Abràmoff MD, Magalhaes PJ, Ram SJ (2004) Image processing with ImageJ. Biophotonics Int 11:36-42.

Adelson EH, Movshon JA (1982) Phenomenal coherence of moving visual patterns. Nature 300:523-525. CrossRef Medline

Albright TD, Stoner GR (1995) Visual motion perception. Proc Natl Acad Sci U S A 92:2433-2440. CrossRef Medline

Andermann ML, Kerlin AM, Roumis DK, Glickfeld LL, Reid RC (2011) Functional specialization of mouse higher visual cortical areas. Neuron 72:1025-1039. CrossRef Medline

Baccus SA, Olveczky BP, Manu M, Meister M (2008) A retinal circuit that computes object motion. J Neurosci 28:6807-6817. CrossRef Medline

Ballas I, Hoffmann KP, Wagner HJ (1981) Retinal projection to the nucleus of optic tract in the cat as revealed by retrograde transport of horseradish peroxidase. Neurosci Lett 26:197-202. CrossRef Medline

Bonin V, Histed MH, Yurgenson S, Reid RC (2011) Local diversity and fine-scale organization of receptive fields in mouse visual cortex. J Neurosci 31:18506-18521. CrossRef Medline

Cahill H, Nathans J (2008) The optokinetic reflex as a tool for quantitative analyses of nervous system function in mice: application to genetic and drug-induced variation. PLoS One 3:e2055. CrossRef Medline

Chen M, Weng S, Deng Q, Xu Z, He S (2009) Physiological properties of direction-selective ganglion cells in early postnatal and adult mouse retina. J Physiol 587:819-828.

Coogan TA, Burkhalter A (1993) Hierarchical organization of areas in rat visual cortex. J Neurosci 13:3749-3772. Medline

Crowder NA, Wylie DR (2002) Responses of optokinetic neurons in the pretectum and accessory optic system of the pigeon to large-field plaids. J Comp Physiol A Neuroethol Sens Neural Behav Physiol 188:109-119. CrossRef Medline

Cruz-Martin A, El-Danaf RN, Osakada F, Sriram B, Dhande OS, Nguyen PL, Callaway EM, Ghosh A, Huberman AD (2014) A dedicated circuit links direction-selective retinal ganglion cells to the primary visual cortex. Nature 507:358-361. CrossRef Medline

Distler C, Hoffmann KP (2001) Cortical input to the nucleus of optic tract and dorsal terminal nucleus (NOT-DTN) in macaques: a retrograde tracing study. Cereb Cortex 11:572-580. CrossRef Medline

Dräger UC (1975) Receptive fields of single cells and topography in mouse visual cortex. J Comp Neurol 160:269-290. CrossRef Medline

Enoksson P (1963) Binocular rivalry and monocular dominance studied with optokinetic nystagmus. Acta Ophthalmol (Copenh) 41:544-563.

Fox R, Todd S, Bettinger LA (1975) Optokinetic nystagmus as an objective indicator of binocular rivalry. Vision Res 15:849-853. CrossRef Medline

Gao E, DeAngelis GC, Burkhalter A (2010) Parallel input channels to mouse primary visual cortex. J Neurosci 30:5912-5926. CrossRef Medline

Gattass R, Sousa AP, Rosa MG (1987) Visual topography of V1 in the Cebus monkey. J Comp Neurol 259:529-548. Medline

Gizzi MS, Katz E, Schumer RA, Movshon JA (1990) Selectivity for orientation and direction of motion of single neurons in cat striate and extrastriate visual cortex. J Neurophysiol 63:1529-1543. Medline

Guo K, Benson PJ, Blakemore C (2004) Pattern motion is present in V1 of awake but not anaesthetized monkeys. Eur J Neurosci 19:1055-1066. CrossRef Medline

Harvey RJ, De'Sperati C, Strata P (1997) The early phase of horizontal optokinetic responses in the pigmented rat and the effects of lesions of the visual cortex. Vision Res 37:1615-1625. CrossRef Medline

Hildreth EC, Koch C (1987) The analysis of visual motion: from computational theory to neuronal mechanisms. Annu Rev Neurosci 10:477-533. CrossRef Medline

Hoffmann KP, Bremmer F, Thiele A, Distler C (2002) Directional asymmetry of neurons in cortical areas MT and MST projecting to the NOT-DTN in macaques. J Neurophysiol 87:2113-2123. CrossRef Medline

Hupé JM, Rubin N (2003) The dynamics of bistable alternation in ambiguous motion displays: a fresh look at plaids. Vision Res 43:531-548. CrossRef Medline

Juavinett A, Callaway E (2015) Pattern and component motion responses in mouse visual cortical areas. Curr Biol 25:1759-1764. CrossRef Medline

Kay NJ, De la Huerta I, Kim IJ, Zhang Y, Yamagata M, Chu MW, Meister M, Sanes JR (2011) Retinal ganglion cells with distinct directional preferences differ in molecular identity, structure, and central projections. J Neurosci 31:7753-7762. CrossRef Medline

Khawaja FA, Tsui JM, Pack CC (2009) Pattern motion selectivity of spiking outputs and local field potentials in macaque visual cortex. J Neurosci 29:13702-13709. CrossRef Medline

Kim J, Wilson HR (1993) Dependence of plaid motion coherence on component grating directions. Vision Res 33:2479-2489. CrossRef Medline

Logothetis NK, Schall JD (1990) Binocular motion rivalry in macaque monkeys: eye dominance and tracking eye movements. Vision Res 30:14091419. CrossRef Medline

Madisen L, Zwingman TA, Sunkin SM, Oh SW, Zariwala HA, Gu H, Ng LL, Palmiter RD, Hawrylycz MJ, Jones AR, Lein ES, Zeng H (2010) A robust and high-throughput Cre reporting and characterization system for the whole mouse brain. Nat Neurosci 13:133-140. CrossRef Medline

Madisen L, Garner AR, Shimaoka D, Chuong AS, Klapoetke NC, Li L, van der Bourg A, Niino Y, Egolf L, Monetti C, Gu H, Mills M, Cheng A, Tasic B, Nguyen TN, Sunkin SM, Benucci A, Nagy A, Miyawaki A, Helmchen F, et al (2015) Transgenic mice for intersectional targeting of neural sensors and effectors with high specificity and performance. Neuron 85:942-958. CrossRef Medline

Margrie TW, Brecht M, Sakmann B (2002) In vivo, low-resistance, wholecell recordings from neurons in the anaesthetized and awake mammalian brain. Pflugers Arch 444:491-498. CrossRef Medline

Marshel JH, Garrett ME, Nauhaus I, Callaway EM (2011) Functional specialization of seven mouse visual cortical areas. Neuron 72:1040-1054. CrossRef Medline

Merabet L, Desautels A, Minville K, Casanova C (1998) Motion integration in a thalamic visual nucleus. Nature 396:265-268. CrossRef Medline

Miyoshi G, Hjerling-Leffler J, Karayannis T, Sousa VH, Butt SJ, Battiste J, Johnson JE, Machold RP, Fishell G (2010) Genetic fate mapping reveals that the caudal ganglionic eminence produces a large and diverse population of superficial cortical interneurons. J Neurosci 30:1582-1594. CrossRef Medline

Moreno-Bote R, Shpiro A, Rinzel J, Rubin N (2010) Alternation rate in perceptual bistability is maximal at and symmetric around equidominance. J Vis 10(11):1 1-18. CrossRef

Movshon JA, Newsome WT (1996) Visual response properties of striate 
cortical neurons projecting to area MT in macaque monkeys. J Neurosci 16:7733-7741. Medline

Movshon JA, Adelson EH, Gizzi MS, Newsome WT (1985) The analysis of moving visual patterns. In: Study week on pattern recognition mechanisms (Chagas C, Gattass R, Gross C, eds), pp 117-151. Rome, Italy: Vatican.

Muir DR, Roth MM, Helmchen F, Kampa BM Model-based analysis of pattern motion processing in mouse visual cortex. Front Neural Circuits 9:38. CrossRef Medline

Naber M, Frässle S, Einhäuser W (2011) Perceptual rivalry: reflexes reveal the gradual nature of visual awareness. PLoS One 6:e20910. CrossRef Medline

Niell CM, Stryker MP (2008) Highly selective receptive fields in mouse visual cortex. J Neurosci 28:7520-7536. CrossRef Medline

Ohki K, Chung S, Ch'ng YH, Kara P, Reid RC (2005) Functional imaging with cellular resolution reveals precise micro-architecture in visual cortex. Nature 433:597-603. CrossRef Medline

Olveczky BP, Baccus SA, Meister M (2003) Segregation of object and background motion in the retina. Nature 423:401-408. CrossRef Medline

Paxinos G, Franklin KB (2001) Mouse brain in stereotaxic coordinates, Ed 2. San Diego, CA: Academic.

Piscopo DM, El-Danaf RN, Huberman AD, Niell CM (2013) Diverse visual features encoded in mouse lateral geniculate nucleus. J Neurosci 33:46424656. CrossRef Medline

Rochefort NL, Narushima M, Grienberger C, Marandi N, Hill DN, Konnerth A (2011) Development of direction selectivity in mouse cortical neurons. Neuron 71:425-432. CrossRef Medline

Rodman HR, Albright TD (1989) Single-unit analysis of pattern-motion selective properties in the middle temporal visual area (MT). Exp Brain Res 75:53-64. Medline

Rubin N, Hupé JM (2004) Dynamics of perceptual bistability: plaids and binocular rivalry compared. In: Binocular rivalry (Alais D, Blakemore R, eds), pp 137-154. Cambridge, MA: MIT.

Rust NC, Mante V, Simoncelli EP, Movshon JA (2006) How MT cells analyse the motion of visual patterns. Nat Neurosci 9:1421-1431. CrossRef Medline

Sakatani T, Isa T (2004) PC-based high-speed video-oculography for measuring rapid eye movements in mice. Neurosci Res 49:123-131. CrossRef Medline

Scannell JW, Sengpiel F, Tovée MJ, Benson PJ, Blakemore C, Young MP (1996) Visual motion processing in the anterior ectosylvian sulcus of the cat. J Neurophysiol 76:895-907. Medline

Schmidt M, Zhang HY, Hoffmann KP (1993) OKN-related neurons in the rat nucleus of the optic tract and dorsal terminal nucleus of the accessory optic system receive a direct cortical input. J Comp Neurol 330:147-157. CrossRef Medline

Simpson WA, Swanston MT (1991) Depth-coded motion signals in plaid perception and optokinetic nystagmus. Exp Brain Res 86:447450. Medline

Smith AT, Harris LR (1991) Use of plaid patterns to distinguish the corticofugal and direct retinal inputs to the brainstem optokinetic nystagmus generator. Exp Brain Res 86:324-332. Medline

Smith MA, Majaj NJ, Movshon JA (2005) Dynamics of motion signaling by neurons in macaque area MT. Nat Neurosci 8:220-228. CrossRef Medline

Solomon SS, Tailby C, Gharaei S, Camp AJ, Bourne JA, Solomon SG (2011) Visual motion integration by neurons in the middle temporal area of a New World monkey, the marmoset. J Physiol 589:5741-5758. CrossRef Medline

Spruston N (2008) Pyramidal neurons: dendritic structure and synaptic integration. Nat Rev Neurosci 9:206-221. CrossRef Medline

Stoner G, Albright D, Ramachandran S (1990) Transparency and coherence in human motion perception. Nature 333:153-155.

Stosiek C, Garaschuk O, Holthoff K, Konnerth A (2003) In vivo two-photon calcium imaging of neuronal networks. Proc Natl Acad Sci U S A 100: 7319-7324. CrossRef Medline

Tinsley CJ, Webb BS, Barraclough NE, Vincent CJ, Parker A, Derrington AM (2003) The nature of V1 neural responses to 2D moving patterns depends on receptive field structure in the marmoset monkey. J Neurophysiol 90:930-937. CrossRef Medline

Tronche F, Kellendonk C, Kretz O, Gass P, Anlag K, Orban PC, Bock R, Klein R, Schütz G (1999) Disruption of the glucocorticoid receptor gene in the nervous system results in reduced anxiety. Nat Genet 23:99-103. CrossRef Medline

Van den Bergh G, Zhang B, Arckens L, Chino YM (2010) Receptive-field properties of V1 and V2 neurons in mice and macaque monkeys. J Comp Neurol 518:2051-2070. CrossRef Medline

Vogelstein JT, Packer AM, Machado TA, Sippy T, Babadi B, Yuste R, Paninski L (2010) Fast nonnegative deconvolution for spike train inference from population calcium imaging. J Neurophysiol 104:3691-3704. CrossRef Medline

Wang Q, Burkhalter A (2007) Area map of mouse visual cortex. J Comp Neurol 502:339-357. CrossRef Medline

Wang Q, Sporns O, Burkhalter A (2012) Network analysis of corticocortical connections reveals ventral and dorsal processing streams in mouse visual cortex. J Neurosci 32:4386-4399. CrossRef Medline

Watanabe K (1999) Optokinetic nystagmus with spontaneous reversal of transparent motion perception. Exp Brain Res 129:156-160. CrossRef Medline

Wei M, Sun F (1998) The alternation of optokinetic responses driven by moving stimuli in humans. Brain Res 813:406-410. CrossRef Medline

Yo C, Demer JL (1992) Two-dimensional optokinetic nystagmus induced by moving plaids and texture boundaries. Invest Ophthalmol Vis Sci 33:2490-2500. Medline 